\title{
Aliança, chefia e regionalismo no Alto Xingu
}

Antonio Roberto Guerreiro Júnior

\section{CpenEdition}

Journals

\section{Edição electrónica}

URL: https://journals.openedition.org/jsa/11902

DOl: 10.4000/jsa. 11902

ISSN: $1957-7842$

\section{Editora}

Société des américanistes

\section{Edição impressa}

Data de publição: 20 dezembro 2011

Paginação: 99-133

ISSN: 0037-9174

\section{Refêrencia eletrónica}

Antonio Roberto Guerreiro Júnior, «Aliança, chefia e regionalismo no Alto Xingu », Journal de la Société des américanistes [En ligne], 97-2 | 2011, mis en ligne le 10 décembre 2014, consulté le 02 septembre 2022. URL : http://journals.openedition.org/jsa/11902 ; DOI : https://doi.org/10.4000/jsa. 11902 


\title{
ALIANÇA, CHEFIA E REGIONALISMO NO ALTO XINGU
}

\author{
Antonio Roberto GUERREIRO Júnior *
}

A partilha de um mesmo sistema de parentesco é um elemento central do sistema político alto-xinguano. Mas o material etnográfico sobre aliança no Alto Xingu é muito restrito, nunca tendo sido alvo de um tratamento detalhado, e pouco dele pôde ser apropriado pelos desenvolvimentos mais recentes da etnologia sul-americana. Neste artigo apresento alguns dados sobre aliança entre os Kalapalo, um grupo caribe alto-xinguano, e exploro a recorrência entre eles do ideal e da prática do casamento matrilateral entre chefes, que coexiste com uma estrutura de troca restrita inclusiva. Veremos que se trata de uma estrutura na qual o regime de aliança dos chefes está duplamente ligado à hierarquia do grupo local e a relações de afinidade entre chefes de diferentes aldeias, o que permite fazer algumas considerações sobre o lugar da aliança e da chefia no sistema regional do Alto Xingu. [Palavras chaves: aliança, política, chefia, Alto Xingu, Kalapalo.]

Alliance, chefferie et régionalisme dans le Haut Xingu. Le partage d'un même système de parenté est l'un des éléments centraux du système politique du Haut Xingu. Mais les données ethnographiques sur l'alliance chez les habitants de cette région ne sont pas abondantes et ont peu fait l'objet d'un traitement détaillé dans les développements les plus récents de l'ethnologie sud-américaine. Dans cet article, seront présentées quelques données sur l'alliance chez les Kalapalo, groupe carib du Haut Xingu, et l'existence chez eux de la pratique du mariage matrilatéral pour des chefs, coexistant avec une structure d'échange restreint inclusif. Nous verrons que, dans une telle une structure, le régime d'alliance des chefs est à la fois lié à la hiérarchie dans le groupe local et aux relations d'affinité entre les chefs des différents villages. Cela nous amènera à réfléchir aux rôles que jouent l'alliance et la chefferie dans le système régional du Haut Xingu. [Mots-clés: alliance, politique, chefferie, Haut Xingu, Kalapalo.]

Alliance, chieftaincy and regionalism in Upper Xingu. The sharing of a kinship system is one of the upper-xinguano political system's central elements. But the ethnographic data on alliance in the Upper Xingu is very limited, having never been subjected to a detailed treatment, and little of it could be appropriated by the most recent developments of south-american ethnology. In this article I present some data on

* Departamento de Antropologia, Universidade de Brasília (DAN/UnB), SGAN 609, Asa Norte, 70910-900, Brasília, DF, Brésil [jrguerreiro@gmail.com].

Journal de la Société des Américanistes, 2011, 97-2, pp. 99-133. C Société des Américanistes. 
alliance among the Kalapalo, an upper-xinguano carib-speaking group, and explore the recurrence among them of the ideal and practice of matrilateral marriage by chiefs, which coexists with a structure of inclusive restricted exchange. We will see that it is a structure in which chiefs' alliance regime is doubly linked to hierarchy within the local group and to affinity relations between chiefs from different villages, which makes it possible to think about roles played by alliance and chieftaincy in the regional system of the Upper Xingu. [Key words: alliance, politics, chieftaincy, Upper Xingu, Kalapalo.]

\section{AlguMas OBSERVAÇões SOBRE MODELOS}

Qual é o sentido de se escrever um artigo ${ }^{1}$ sobre sistemas de aliança hoje em dia, quando já se argumentou tantas vezes sobre a inexistência, para os povos indígenas, de um objeto chamado " parentesco » que se assemelhe aquilo que projetamos neles ao formularmos muitas de nossas questões sobre este tema (Schneider 1965)? Esta é uma questão importante de ser feita, tendo em vista os excessos cometidos por tantos estudos formalistas que isolaram o parentesco como se ele pudesse ser abstraído de suas infinitas correlações com a vida social e ser transformado em uma realidade autônoma.

Ao isolar regras de casamento e filiação, muitas vezes acabamos descaracterizando formas complexas de socialidade: onde às vezes insistimos em procurar regras e desvios, os índios frequentemente vêem histórias de vida, circulação de pessoas, substâncias, objetos, nomes - tudo relacionado de maneiras muito diversas, sempre contextuais, dificilmente se prestando a qualquer formalização que a ideia de « regra » possa impor (Strathern 2006). A antropologia pagou um preço caro por separar o parentesco e a aliança destes aspectos centrais para a produção da socialidade indígena, pois desde pelo menos a década de 1960 tem havido um enorme esforço para juntá-las (Wagner 1967; 1977): o esforço de retomar a produção ou decomposição da pessoa como articulações diferenciais dos processos de relacionamento (aparentamento) de sujeitos, e pensar as relações ditas « de parentesco » como momentos mais ou menos específicos de produção da socialidade em geral (Costa 2007; Gow 1991; McCallum 1996; Viveiros de Castro 2002a).

Mas isto não implica necessariamente que os aspectos formais das terminologias, das práticas de casamento e suas formas correlatas de troca não tenham nenhuma importância de fato. Pelo menos no que toca ao tema deste artigo há boas razões para se ocupar com estas questões, pois a preocupação dos alto-xinguanos com a aliança e a troca em geral parece peculiar quando comparada à paisagem amazônica mais geral (ou ao menos à imagem que a antropologia fez dela): enquanto em boa parte dos povos das terras baixas da América do Sul encontraríamos sistemas de trocas pouco elaborados, sistemas de aliança que gravitam muito em torno da troca simétrica e endogâmica e uma pequena ênfase na organização sociopolítica (a caracterização geral 
feita por Descola 2001, p. 108), no Alto Xingu as trocas cerimoniais, as formas de exogamia (de parentela e de grupo local), a troca assimétrica e a sociopolítica são temas bastante relevantes, e uma investigação sobre estas questões, como já bem mostrou Barcelos Neto (2003, passim; 2008, p. 29), pode ter repercussões interessantes para a compreensão do sistema político regional alto-xinguano.

Os avanços no campo das teorias da aliança e da etnologia ameríndia permitem hoje integrar aspectos da produção da pessoa e da sua inserção em redes de parentesco (que se estendem muito além as fronteiras da humanidade no sentido moderno ${ }^{2}$ ) a diferentes instâncias ou momentos de processos mais gerais de produção da socialidade (Costa 2007; Gow 1997; Viveiros de Castro 2001). Como tem sido amplamente explorado em outros contextos etnográficos, os modelos de aliança de casamento praticados pelos Kalapalo também estão intimamente ligados à produção de sua socialidade específica no cosmos e no complexo xinguano (Gregor 2001). Muitas sociocosmologias amazônicas associam o "exterior », a alteridade, seja ela humana ou não, à afinidade potencial ou sociopolítica, isto é, a formas de afinidade que, segundo Viveiros de Castro (2002a, p. 157) abrem a « introversão localista do parentesco ao comércio com a exterioridade [...] » e articulam termos não ligados pelo casamento. Ainda segundo este autor (ibid.), « o verdadeiro afim é aquele com quem não se trocam mulheres, mas outras coisas: mortos e ritos, nomes e bens, almas e cabeças ». Esta forma de conceber a afinidade seria característica das «economias políticas da predação » ou " economias simbólicas da alteridade » (Viveiros de Castro 1996, p. 190), nas quais a não-troca, a não-aliança, pensada e praticada frequentemente pela guerra, pela captura, pela transformação no Outro e, claro, pelo canibalismo, se apresenta como modelo de produção de relações, pessoas e coletivos.

Uma característica interessante da cosmologia kalapalo é que ela destoa em alguma medida destas economias políticas predatórias «típicas ». Trata-se de uma cosmologia que reconhece a predação e a afinidade potencial como « dados » ontológicos, como algo da ordem do inato, mas que está lá para ser enfrentado e combatido pelos "verdadeiros humanos" (kuge hekugu, em kalapalo). No início dos tempos (ingila), o encontro de um humano com um ser-espírito (itseke) ou um humano não xinguano (ngikogo), por exemplo, frequentemente significava um confronto iminente; e hoje os seres-espíritos estão o tempo todo desejando capturar as almas-sombras (akuã) dos humanos, e a visão de um itseke pode significar a morte. Mas os rituais de cura e pós-cura de doenças causadas por itseke tematizam justamente um complexo movimento de transformação da predação improdutiva e mortal praticada pelos itseke em familiarização (como o conceito de Fausto 1999), através da troca da alma roubada por objetos valiosos e da oferta de comida aos seres causadores de doenças (Barcelos Neto 2006; Cardoso 2004; Novo 2008). A « predação inata » 
que marca o começo dos tempos e algumas das relações entre humanos e seres-espíritos, quando incontrolada, é tematizada de várias maneiras como algo improdutivo - a caça recebe um valor negativo do ponto de vista do comportamento ideal alto-xinguano, e bens culturais como o fogo, a água, os colares de concha de caramujo, o urucum, o jenipapo, etc. só puderam ser obtidos através da substituição de relações de guerra/predação por relações de troca. E este processo é muitas vezes acompanhado da transformação da afinidade potencial que caracteriza inimigos em afinidade efetiva por meio de alianças matrimoniais entre os humanos e outros seres (também humanos de seus próprios pontos de vista): em algumas das narrativas de criação do mundo humano, os gêmeos Sol (Taũgi) e Lua (Aulukumã) e outros heróis culturais, quando obtém algum elemento importante da cultura xinguana às vezes também recebem esposas - evidenciando como a troca de mulheres é um elemento central neste processo de luta anti-predatória na construção do mundo xinguano.

O roubo e a captura, como tematizados em outras cosmologias ameríndias, não lhes parecem apropriados - é preciso o tempo todo inventar a troca. Como se estivessem engajados em uma luta política na paisagem ameríndia, os Kalapalo realizam um grande esforço para transformar a predação em troca, desvinculando a afinidade potencial da violência que lhe é imanente e transformando Outros em aliados através de trocas e casamentos. Em boa parte da mitologia e do ritual, a pacificação do Outro é descrita a partir da troca simétrica ou da doação assimétrica de mulheres ${ }^{3}$. Na vida das pessoas, estes dois modelos de aliança matrimonial, a troca simétrica (representada pelo casamento de primos cruzados bilaterais, pela troca de irmãs em gerações não-consecutivas e pelo casamento patrilateral ${ }^{4}$ ) e a troca assimétrica (representada pelo casamento matrilateral), orientam a maior parte das práticas matrimoniais kalapalo e, assim como na mitologia e no ritual, estão diretamente ligados à produção da socialidade em um universo repleto de Outros, afins reais e afins potenciais - no qual os chefes (ou « nobres ${ }^{5} »$ em geral) e os casamentos assimétricos desempenham um papel mediador central.

Os Kalapalo se referem a alguns homens e mulheres como anetü e itankgo, « chefe » e « chefa », respectivamente, e títulos equivalentes existem entre todos os grupos da região ${ }^{6}$. Trata-se de uma condição ao mesmo tempo hereditária (que se herda pela linha paterna ou materna) e desenvolvida no decorrer da vida, pois não basta ser filho ou neto de anetaõ (plural de anetü) para também sê-lo, mas é indispensável desenvolver um corpo belo e forte, um comportamento sereno e generoso, e uma série de habilidades linguísticas indispensáveis para o exercício de suas funções rituais (Franchetto 1986; 1993; 2000). Os parentes dos anetaõ também são considerados « pessoas importantes » de alguma maneira, apesar de não possuírem nenhum título. São, segundo dizem os Kalapalo, « pessoas bonitas », que mesmo que não se tornem chefes têm o direito de serem 
enterradas no centro da aldeia em uma cova especial e terem um ritual pós-funerário (egitsü) realizado em sua memória. A este conjunto de pessoas (os chefes e seus parentes), me refiro como nobres, reservando « chefes » apenas para aqueles que são chamados de anetaõ.

Vários autores já observaram que no Alto Xingu existem regimes matrimoniais distintos para nobres e não-nobres, mas sem se aprofundar muito na questão. Galvão (1979) e Oberg (1953) já haviam comentado que entre os Kamayurá (tupi alto-xinguanos) haveria uma certa endogamia de status produzida pela prática do casamento avuncular entre os « capitães » (forma pela qual os alto-xinguanos se referiam aos chefes no contex to inicial do contato com a sociedade nacional). Barcelos Neto (2003, p. 68) afirma que entre os Wauja (falantes de aruak) há uma forte tendência dos nobres se casarem apenas entre si, no intuito de conservarem a " substância nobre ${ }^{7}$ » hereditária que os distingue dos demais por nascimento e que permite que eles eventualmente se tornem chefes ativos através de sua potencialização por meio de rituais. Entre os Kuikuro (falantes de karib, como os Kalapalo), Heckenberger (2005, p. 264) também menciona que os casamentos dos chefes e seus filhos tendem a ser « politicamente endogâmicos ", sendo sempre realizados através de noivados arranjados por suas famílias. Entretanto, os dados disponíveis sobre casamento entre estes e outros grupos alto-xinguanos (tais como posições genealógicas dos cônjuges, justificativas para as uniões e frequências estatísticas dos tipos de casamento) são muito restritos, fragmentados e confusos para poderem ser utilizados em um estudo detalhado sobre a aliança e suas implicações no sistema político da região. Esta fragmentação dos dados, em conjunto com a importância conceitual (nos mitos) e prática (no ritual e nos arranjos matrimoniais) que a aliança tem para os Kalapalo foram os principais motivos que me levaram a conduzir uma pesquisa sobre este tema.

Heckenberger (2005, pp. 264-265) afirma que o parentesco Kuikuro se adéqua ao modelo do dravidianato amazônico, o que estaria de acordo com as hipóteses mais gerais de Viveiros de Castro (1993a; 2002a) sobre os sistemas de aliança das terras baixas da América do Sul e a hipótese de Coelho de Souza (1992; 1995) sobre o parentesco xinguano. Estes autores argumentam que o sistema de aliança alto-xinguano (assim como outros sistemas amazônicos) seria uma forma de sistema multibilateral, ou de troca restrita inclusiva, baseado nas formas da troca restrita (a troca de irmãs e o casamento patrilateral) com um número de parceiros não-redutíveis a múltiplos de 2 . As relações de casamento seriam reguladas por um princípio simétrico evolvendo um universo de afins reais e afins possíveis. Mais especificamente, o sistema xinguano poderia ser descrito como um sistema de " aliança iroquesa », isto é, um sistema de troca restrita inclusiva operando em regime não-elementar, baseado na troca de irmãs em gerações não-consecutivas através do casamento de filhos de primos cruzados de sexo oposto (Viveiros de Castro 1998). 
Basso (1973a; 1973b; 1975; 1985; 1986; 1995; 2001), que possui uma obra muito extensa sobre os Kalapalo, foi a primeira a mencionar a semelhança do sistema kalapalo com os sistemas dravidianos, por causa da coincidência dos termos para irmão da mãe (MB $\left.{ }^{8}, a w a\right)$ e irmã do pai (FZ, etsi) com aqueles para sogro (WF) e sogra (WM), mas não apresenta dados sobre muitos casos de aliança matrimonial (ver Basso 1973a; 1975). Como veremos, a lógica kalapalo de classificação dos parentes e do espaço social em geral corresponde ao modelo dos sistemas dravidianos de "fórmula rica " (isto é, sistemas dravidianos não-elementares) tal como definidos por Taylor (1998), e o sistema de aliança apresenta em comum com outros sistemas amazônicos várias formas de troca restrita inclusiva, operando em regime não-elementar: troca de irmãs em gerações não-consecutivas, casamento de filhos primos cruzados bilaterais e casamentos com a FZD $^{9}$. A princípio estas características permitiriam facilmente classificar o sistema de aliança kalapalo no conjunto do dravidianato amazônico sem problemas - não fosse uma curiosa preferência pelo casamento com a prima cruzada matrilateral. Quando comecei a me deparar com esta preferência no discurso de muitos interlocutores, nas estatísticas dos casamentos e com a marcação da relação entre tio materno e sobrinho uterino em algumas narrativas, imaginei que eu eventualmente pudesse de algum modo identificar as sogras dos homens casados com primas matrilaterais como suas tias paternas ${ }^{10}$ (pois seria possível que suas WM também fossem FZ, ou mulheres que recaíssem na categoria FZ pelos cálculos de cruzamento, mas que os interlocutores não explicitassem isso), o que permitiria incluir estes casamentos no quadro geral da troca restrita e dos outros sistemas amazônicos. Entretanto, na grande maioria destes casos minha suposição se mostrou incorreta e, não obstante, quanto mais eu perguntava sobre as preferências kalapalo sobre o casamento, mais eu me deparava com a existência de uma ideologia matrilateral que enfatizava de maneiras diversas a ideia de que a esposa ideal deveria ser filha de um tio materno.

A princípio, a coexistência destas diferentes modalidades de aliança (que sugeriria um sistema de casamento de primos ambilaterais) com uma preferência matrilateral poderia parecer uma contradição quando pensada exclusivamente de um ponto de vista interno ao sistema de aliança, mas que pode ser útil para pensar dois elementos clássicos dos estudos sobre os povos daquela região - a chefia e o regionalismo - pois, como veremos, os casamentos matrilaterais estão ligados a ambos. Por um lado, os casamentos matrilaterais são uma preferência explícita dos nobres e, sobretudo, dos principais chefes (um jovem e promissor anetü idealmente deve ficar noivo de uma MBD), e isto é evidenciado pela recorrência desta forma de casamento entre esta categoria de pessoas; por outro, parte considerável dos casamentos com a MBD é realizada entre os mais importantes chefes de aldeias diferentes (e não necessariamente pertencentes à mesma etnia) e com residência 
virilocal (anetã̃ «pequenos » geralmente se casam no grupo local e mantêm residência uxorilocal).

O resultado é uma rede de afinidade entre nobres de aldeias diversas na qual os grandes chefes na maioria das vezes conseguem driblar seus afins em posição superior (doadores de esposas) através da residência virilocal e, em seus próprios grupos locais, ainda agregam afins na condição de receptores de esposas (seus sobrinhos uterinos, casados com suas filhas, ou primos cruzados patrilaterais, casados com suas irmãs), hierarquicamente inferiores a eles no sistema de « vergonha » (ihütisu) que regula as relações entre afins em posições distintas. Como espero que fique claro ao final deste artigo, a dualidade de regimes matrimoniais entre nobres e « comuns ${ }^{11}$ » deve ser vista como parte do processo geral de produção da socialidade kalapalo tanto ao nível do grupo local quanto no plano de sua inserção nas redes que conectam os povos que formam a « sociedade xinguana ». Quero mostrar como a aliança, nas suas formas simétricas e assimétricas, é para os Kalapalo uma prática cujos modelos são constitutivos de seus modos mais amplos de estar no mundo e de se relacionar com Outros que o compartilham (seres-espíritos e outros coletivos indígenas). Espero que o que apresento a seguir possa ajudar a compreender algumas relações entre aliança, chefia e regionalismo no Alto Xingu e incentivar o estudo do papel do parentesco na produção da socialidade complexa que caracteriza aquela região.

\section{OS « PARAdOXOS » DO PARENTESCO XINGUANO E A ALIANÇA IROQUESA}

Os Kalapalo falam uma variante da língua karib do Alto Xingu e vivem na região do rio Culuene, um dos formadores do rio Xingu, no Parque Indígena do Xingu (MT, Brasil). Eles são um dos dez povos que formam o Alto Xingu, área etnográfica que ficou famosa na literatura pelas grandes semelhanças sócio-cosmológicas entre os grupos que a compõem, falantes de línguas pertencentes a famílias distintas ${ }^{12}$, e fortemente interligados por relações de casamento, rituais, trocas econômicas e acusações de feitiçaria ${ }^{13}$. Atualmente os Kalapalo somam cerca de 532 pessoas e vivem distribuídos majoritariamente em dez aldeias, sendo duas « aldeias de verdade ${ }^{14}$ » ( ete hekugu) e oito aldeamentos pequenos ${ }^{15}$. Os Kalapalo consideram aldeias de verdade aquelas que se adéquam ao padrão de aldeia circular, com uma casa das flautas (kuakutu) no centro da aldeia (que oculta as flautas kagutu dos olhos das mulheres, por isso também chamada de « casa dos homens »), que possuem chefes legítimos e que realizam rituais.

Uma das dificuldades de se escrever um texto sobre um povo alto-xinguano é que o risco de se estender irrefletidamente características da realidade do grupo local ao complexo regional e vice-versa é muito grande, e as chances de se 
produzir ao mesmo tempo generalizações duvidosas ou deduções superficiais são várias. Não pretendo falar sobre « o Alto Xingu » como área etnográfica, o que seria impossível, dado o volume de informações que existem sobre os povos da região e seus vizinhos. Além do mais, como as pesquisas recentes mostram, assim como parece haver uma estrutura de longa duração por trás do desenvolvimento daquela região (Heckenberger 2001; 2005) as particularidades de cada grupo são grandes o suficiente para se considerar cada visão local como o resultado de interações diversificadas que cada povo mantém com o sistema regional (Bastos 1983, 1995; Coelho de Souza 2001). Assim, como minha experiência de campo se restringe aos Kalapalo da aldeia Aiha, o que eu espero oferecer aqui é uma visão apenas parcial (e, claro, historicamente datada) do regionalismo alto-xinguano e da chefia a partir de uma descrição específica da forma como as práticas de aliança dos Kalapalo podem estar ligadas à sua participação atual no sistema político xinguano. A maioria dos meus dados genealógicos têm profundidade de no máximo quatro gerações (pois a memória genealógica dos Kalapalo se interessa menos por profundidade vertical do que por extensão horizontal ${ }^{16}$ ), e a repetição dos fenômenos discutidos abaixo é algo que ainda precisa ser mais bem explorado no futuro.

Os Kalapalo, assim como os demais grupos alto-xinguanos, não possuem nenhum tipo de sistema de distribuição das pessoas em grupos corporados baseados no parentesco, tais como clãs, metades ou linhagens, que eventualmente possam equivaler a « unidades de troca » no sistema de aliança. Eles também não contam com grupos corporados baseados em princípios como a onomástica, o pertencimento a classes de idade ou a grupos cerimoniais, como é o caso de diversos grupos de língua jê e bororo do Brasil Central (ver Coelho de Souza 2002 para mais informações sobre o parentesco entre os jê). Ao invés disso, como é comum entre a maioria das sociedades das terras baixas da América do Sul, os Kalapalo possuem descendência cognática (traçada simultaneamente pelas linhas materna e paterna), sem qualquer divisão de privilégios de herança material ou estatutária por uma ou por outra. Em consonância com o cognatismo, os Kalapalo possuem uma terminologia de parentesco simétrica, que distingue entre parentes paralelos e cruzados sem diferenciar relações de parentesco traçadas via linha materna ou paterna, característica também compartilhada pelos demais povos alto-xinguanos - à exceção dos Trumai, que parecem ser os únicos que possuem «termos descritivos que explicitam a diferença entre [primos cruzados] patrilaterais e matrilaterais ${ }^{17} \gg$ (Monod Becquelin e Guirardello 2001, p. 427).

Este tipo de terminologia costuma estar associada às diversas formas da troca restrita e, especificamente, aos sistemas de casamento de primos cruzados bilaterais ou ambilaterais, e a coincidência destas características permitiria situar os Kalapalo no panorama amazônico mais amplo, no qual parecem predominar sistemas cognáticos e terminologias simétricas acompanhados de variações do 
casamento de primos (Viveiros de Castro e Fausto 1993). Entretanto, o estatuto deste tipo de aliança no Alto Xingu é ambíguo desde as primeiras etnografias. Oberg (1953, p. 7), em sua pesquisa sobre os Kamayurá, descreveu o casamento de primos bilaterais como uma regra positiva, afirmando que a escolha do cônjuge seria normalmente realizada pelos pais dos futuros esposos e que outras formas de casamento somente seriam aceitas no caso da indisponibilidade do cônjuge prescrito. Diferentemente, Galvão (1979, p. 28), que também fez pesquisa junto aos Kamayurá, afirma que apesar da terminologia simétrica ele não pôde registrar mais do que apenas dois casamentos de primos cruzados, e que na prática a maioria das pessoas seriam casadas com não-parentes que elas mesmas escolheram para cônjuges (uma imagem incrivelmente dissonante da que Oberg oferece, considerando-se a proximidade das duas pesquisas ${ }^{18}$ ). Posteriormente, Zarur (1975, p. 29) registrou uma grande quantidade de casamentos de primos cruzados bilaterais entre os Aweti, sugerindo que a aldeia aweti possuiria uma forma de organização dualista. Basso (1973a; 1975) também identificou entre os Kalapalo uma preferência pelo casamento de primos cruzados, mas não apresentou em seus trabalhos dados sobre os tipos de casamentos existentes (não especifica as uniões como casamentos de primos bi, patri ou matrilaterais, assim como também não oferece nenhuma estatística dos casamentos ${ }^{19}$ ).

E assim como o casamento de primos cruzados, os (raros, é fato) registros das terminologias de parentesco xinguanas também são ambíguos e pouco detalhados. As únicas informações que se tem sobre a aplicação de termos de parentesco entre parentes colaterais e cálculos de cruzamento são entre os Kuikuro (Dole 1969) e Mehináku (Gregor 1977), que apresentam feições iroquesas (isto é, filhos de parentes cruzados de mesmo sexo são classificados como paralelos e filhos de primos cruzados de sexo oposto são classificados como cruzados). Para os Kalapalo, Basso não dá nenhuma informação sobre as transformações da terminologia entre parentes colaterais, e em seus trabalhos não há informações sobre a classificação de filhos de parentes cruzados [além de não encontrarmos menções às distinções de idade entre germanos, o que no trabalho de Coelho de Souza (1992) foi tido como uma característica peculiar das terminologias aruak]. Não vem ao caso detalhar a terminologia e os vocativos, mas uma lista simples de termos de parentesco e os cálculos de cruzamento (para Ego masculino ${ }^{20}$ ) pode ser resumida da seguinte forma (Figura 1): 


\begin{tabular}{|c|c|}
\hline \begin{tabular}{|c|} 
Termos de referência (3a \\
pessoa, Ego masculino)
\end{tabular} & Marcadores \\
\hline \multicolumn{2}{|c|}{$\mathrm{G}^{+3}$} \\
\hline ngaupügü kuegü & FFF, FMF, MFF, MMF \\
\hline intsü kuegü & FFM, FMM, MFM, MMM \\
\hline \multicolumn{2}{|r|}{$\mathrm{G}^{+2}$} \\
\hline ngaupügü & $\begin{array}{c}\text { FF, MF, FFB, FF } \delta \text { X, FMB, } \\
\text { MFB, } \\
\text { MF } \delta X, M M B\end{array}$ \\
\hline intsü & $\begin{array}{c}\text { FM, MM, FMZ, FM어, } \\
\text { FFZ, MMZ, } \\
\text { MM어, MFZ }\end{array}$ \\
\hline \multicolumn{2}{|c|}{$\mathrm{G}^{+1}$} \\
\hline suün & $F, F B, F \delta X$ \\
\hline isi & $\mathbf{M}, \mathbf{M Z}, \mathbf{M} \delta \mathrm{X}$ \\
\hline ijogu & MB, Mo X, WF \\
\hline itsügü & FZ, FOPX, WM \\
\hline \multicolumn{2}{|c|}{$\mathrm{G}^{\varnothing}$} \\
\hline ihisuüngü & B, FBS, MZS \\
\hline ihinhano & $\mathrm{eB}$ \\
\hline$i h i s \ddot{u}$ & yB \\
\hline ingadzu & Z, FBD, MZD \\
\hline ihaün & $\begin{array}{c}\text { FZCh, MBCh, Fo+XCh, } \\
\text { M } \delta \text { XCh }\end{array}$ \\
\hline \multicolumn{2}{|c|}{$\mathrm{G}^{-1}$} \\
\hline ijimo & $\mathrm{Ch}$ \\
\hline inhugu & $\mathrm{S}, \mathrm{BS}, \boldsymbol{\delta} \mathrm{XS}$ \\
\hline indisü & $\mathrm{D}, \mathrm{BD}, \delta \mathrm{XD}$ \\
\hline ihatuün & ZS \\
\hline ihati & $\mathrm{ZD}$ \\
\hline \multicolumn{2}{|c|}{$\mathrm{G}^{-2}$} \\
\hline ihijaõ & $\mathrm{ChCh}$ \\
\hline
\end{tabular}

FIG. 1 - Terminologia de parentesco kalapalo para Ego masculino (os termos de referência estão na $3^{\text {a }}$ pessoa do singular).

A lógica classificatória obedece aos cálculos iroqueses, segundo os quais (Figura 2):

\begin{tabular}{|c|c|}
\hline $\mathrm{F} \hat{O} \mathrm{X}=\mathrm{F}$ & $\mathrm{M} O \mathrm{XD}=\mathrm{Z}$ \\
\hline $\mathrm{F} \not \mathrm{XS}=\mathrm{B}$ & $\mathrm{M} \delta^{1} \mathrm{X}=\mathrm{MB}$ \\
\hline $\mathrm{F} \hat{\gamma} \mathrm{XD}=\mathrm{Z}$ & $\mathrm{M}{ }^{8} \mathrm{XCh}=\mathrm{X}$ \\
\hline $\mathrm{F} \bigcirc \mathrm{X}=\mathrm{FZ}$ & ${ }^{f} \mathrm{XCh}=\mathrm{Ch}$ [h. f.] \\
\hline $\mathrm{F} O \mathrm{XCh}=\mathrm{X}$ & $O \mathrm{XCh}=\mathrm{ZCh}[\mathrm{h} . \mathrm{f}]$. \\
\hline $\mathrm{M} \odot \mathrm{X}=\mathrm{M}$ & 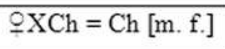 \\
\hline $\mathrm{M} \odot \mathrm{XS}=\mathrm{B}$ & $\begin{array}{c}\mathrm{XCh}=\mathrm{BCh}[\mathrm{m} . \\
\text { f.] }\end{array}$ \\
\hline
\end{tabular}

FIG. 2 - Cálculos classificatórios (iroqueses) da terminologia kalapalo. 
Como se vê pelas Figuras 1 e 2, a terminologia de parentesco kalapalo apresenta a grande maioria das características compartilhadas pelas terminologias dos demais povos do Alto Xingu: classificação simétrica com bifurcação (cruzamento) nas três gerações centrais; uma deriva havaiana em GØ; vocativos para « sogro » e « sogra » que coincidem com os termos para MB e FZ [sugerindo semelhanças com os sistemas dravidianos, como já haviam indicado Basso (1973a; 1975) e Gregor (1977)]; cálculos iroqueses de cruzamento; e, apesar de eu não apresentá-los aqui por uma questão de economia de espaço, termos específicos para afins (para mais detalhes, ver Guerreiro Júnior 2008, p. 217).

A coexistência destas características criou alguns problemas para os antropólogos, pois trata-se de uma terminologia que, segundo as tipologias tradicionais, sugerem práticas matrimoniais aparentemente incompatíveis entre si (Godelier, Trautmann e Tjon Sie Fat 1998; Lounsbury 1964; Trautmann e Barnes 1998). Enquanto a havaianização em GØ e os cálculos iroqueses, normalmente associados a sistemas de aliança não-elementares, sugerem a proibição do casamento de primos e apontam para uma regulação da aliança por fatores extra-parentesco, as feições dravidianas da terminologia sugerem um caráter prescritivo do casamento de primos cruzados bilaterais. De modo geral, boa parte das discussões sobre o parentesco xinguano girou em torno de dois supostos " paradoxos », um interno à terminologia, conhecido como " paradoxo havaiano-iroquês » (Coelho de Souza 1995), e outro relativo à combinação entre cálculos iroqueses e casamentos de primos. Contudo, estes paradoxos só são problemáticos para os antropólogos quando insistem em diferenciar modelos e práticas matrimoniais, pois como veremos a solução se encontra na pragmática das relações sociais. Como outros autores já discutiram (Fausto 1995), o próprio modelo inclui sua manipulação, e as próprias « regras » são de fato práxis (ibid., p. 104).

$\mathrm{O}$ primeiro paradoxo diz respeito à coexistência de uma terminologia cruzada-iroquesa com uma classificação geracional-havaiana em GØ. É comum encontrar nas etnografias a descrição de primos cruzados que se referem como irmãos, e entre os Kalapalo não é diferente. A palavra uhisuüngü ( meu irmão ») é um termo bastante englobante que, dependendo do nível de contraste, pode incluir os primos cruzados de Ego (e no limite do englobamento, uhisuüngü refere-se a todos os parentes de Ego, ou até mesmo a todos os moradores de uma mesma aldeia). Basso (1973a; 1975) já havia notado esta tendência para classificar primos cruzados como irmãos, e sugere que isso seria o resultado de uma preferência pelo casamento com parentes distantes diretamente ligada ao complexo da feitiçaria: ao se casar com parentes distantes, um indivíduo agregaria mais aliados, evitando acusações de feitiçaria, ou garantiria abrigo em outras aldeias caso alguma acusação recaísse sobre ele.

De fato, a distância social é um dos critérios pertinentes para a escolha do cônjuge e a feitiçaria sem dúvida alguma influencia decisivamente a escolha dos 
afins; entretanto, esta relação entre proximidade/consanguinidade e distância/ afinidade parece ser mais do que isso, pois é central para a forma como os ameríndios concebem o espaço social. Os Kalapalo associam este processo de consanguinização dos primos cruzados à distância social relativa entre o referente e o referido, incluindo nesta categoria somente os primos cruzados próximos. Normalmente, todos os primos cruzados de primeiro grau são assimilados a irmãos; em segundo lugar, primos cruzados genealogicamente mais distantes, porém co-residentes, também tendem a ser transformados em germanos; por fim, os afins reais também são pensados como um tipo de « super-consanguíneos », objeto de extremo respeito. O que está por trás desta tendência é um critério de distância social segundo o qual a consanguinidade coincide com a proximidade geográfica, a partilha de substâncias, a co-residência e o comensalismo. Os afins possíveis (afins em potencial) se restringem aos parentes distantes, e é apenas com eles que uma relação de aliança pode ser produzida sem contradizer os princípios da proximidade/consanguinidade. No caso kalapalo, estas pessoas podem ser primos cruzados de segundo grau, primos cruzados de primeiro grau de aldeias diferentes e pessoas que se dizem não aparentadas. Vale a pena notar que o termo em português que pessoas que não têm relações de parentesco usam para se referir umas às outras quando se tornam amigos ou parceiros de troca é justamente « primo ».

Longe do núcleo da parentela todos são afins potenciais, e a afinidade real só se realiza com esta categoria de pessoas. É uma forma extremamente produtiva de se conceber a aliança, pois as redes de parentesco tendem a se expandir cada vez mais, já que a cada casamento e cada nascimento mais distância social é necessária para que um parente cruzado possa recair no espaço da afinidade potencial e ser transformado em afim efetivo (Coelho de Souza 1995). Em suma, ao invés de representar um paradoxo, a existência de traços havaianos em uma terminologia iroquesa apenas representa uma estrutura concêntrica que opõe consanguíneos e afins potenciais (exatamente como uma estrutura dravidiana), revelando uma estrutura conceitual dual (consanguíneos/afins) sob uma terminologia triádica (consanguíneos/cruzados/afins).

Taylor (1998) encontrou um sistema exatamente deste tipo entre os Aguaruna do complexo Jívaro (que em seu estudo também inclui os Achuar, Shuar e Candoshi). A autora desenvolveu o argumento de que as terminologias iroquesas e dravidianas, ao invés de apontarem para estruturas completamente distintas, são na verdade diferentes modalidades de uma estrutura comum. O sistema Achuar se aproxima muito do modelo dravidiano clássico, contando com regra de casamento de primos cruzados bilaterais próximos e não apresenta termos separados de afinidade, enquanto o sistema Aguaruna é um exemplo claro de como uma terminologia iroquesa pode operar de acordo com uma lógica dravidiana. Neste sistema, os cálculos iroqueses coexistem com uma regra de assimilação de primos cruzados de sexo oposto de primeiro grau a irmãos 
(havaianização em GØ), que proíbe o casamento entre eles (considerados próximos demais para se casar). Consequentemente, pelos cálculos iroqueses, seus filhos são considerados primos cruzados, vistos como distantes o suficiente para se casarem, e são considerados cônjuges ideais. Efetivamente, é entre esta categoria de parentes que ocorre a maioria dos casamentos entre os Aguaruna [" 50 percent of the 70 percent of marriage between "cousins" " (in Taylor 1998, p. 193)]. Ou seja, a maioria dos casamentos de primos se dá entre filhos de primos cruzados de sexo oposto: a terminologia, neste caso, não funciona no sentido de definir para Ego um campo matrimonial (como nos sistemas dravidianos clássicos), mas sim para seus filhos. Visto de uma perspectiva diacrônica, o sistema aguaruna também é fundado sobre a oposição entre consanguíneos (Ego e seus primos cruzados de primeiro grau inclusos) e afins (filhos de primos cruzados de sexo oposto) e transmite relações de aliança genealogicamente, mas sob a condição de atrasar o seu redobramento das alianças em uma geração.

É sob esta ótica que Taylor (1998) argumenta que o sistema aguaruna é uma variação de sistema dravidiano, mas que transmite a afinidade através de cálculos iroqueses. Ele seria um sistema dravidiano de " fórmula rica » ou « complexa » (ibid., p. 209), por oposição aos sistemas dravidianos comuns (como o Tamil, descrito por Dumont, ou o Achuar descrito pela autora). Isto explicaria a tripartição da terminologia evidenciada pela existência de termos específicos para afins, pois mostra que uma divisão tripla da terminologia e do sistema matrimonial pode aderir estritamente a uma sócio-lógica dravidiana, dual, de oposição entre consanguíneos e afins, " both because it supposes and reproduces a perennialized alliance relationship and because it plays exclusively on the necessary and sufficient distinction between affinity and consanguinity" (ibid., p. 195). E como complementa a autora (ibid., p. 208), "From this standpoint, the Aguaruna variant corresponds perfectly to the spirit if not the letter of the Dravidian model as defined by Dumont $»$.

Num sentido geral, o mesmo é válido para os Kalapalo, entre os quais a maioria dos casamentos se dá entre filhos de primos cruzados de sexo oposto. Minha genealogia conta com 242 casamentos, dos quais apenas 51 serão analisados neste artigo, e se referem aos homens atualmente casados em Aiha, seus pais e alguns de seus avós. Como a profundidade genealógica é pequena e a partir da segunda geração ascendente as informações se tornam complicadas, optei por analisar apenas os casamentos sobre os quais eu disponho de informações genealógicas precisas e detalhadas. Destes 51, 88 \% são entre primos cruzados de segundo grau (um número proporcionalmente maior do que o encontrado entre os Aguaruna), e há apenas quatro casamentos entre primos de primeiro grau (todos com a MBD). Vejamos a tabela abaixo, que representa o percentual de casamentos de primos em Aiha (Figura 3): 


\begin{tabular}{|c|c|c|}
\hline Tipos de uniões & Total & Percentual \\
\hline Casamentos com a FZD & 16 & $31 \%$ \\
\hline Casamentos com a MBD & 27 & $53 \%$ \\
\hline Casamentos de primos cruzados bilaterais & 8 & $16 \%$ \\
\hline Total & $\mathbf{5 1}$ & $100 \%$ \\
\hline
\end{tabular}

FIG. 3 - Percentual de tipos de casamentos de primos.

Na tabela acima não diferencio o grau de parentesco entre os primos cruzados, pois a terminologia kalapalo também não o faz: todas as pessoas que se classificam como primos cruzados, seja por qual via, estão inclusas ${ }^{21}$. Certamente para uma análise interessada em circuitos de troca ou redes sociais, seria fundamental especificar de que tipo de primos estamos falando. Afinal, o atraso de pelo menos uma geração para o redobramento de uma aliança faz com que a cada geração antigas alianças sejam atualizadas ou novos parceiros entrem nos circuitos ${ }^{22}$. Mas é a caracterização de alguém como primo cruzado e a possibilidade de transformar tal ou qual parente cruzado em afim que me interessa aqui. Insistir na necessidade de especificar os laços genealógicos em uma situação etnográfica na qual os próprios índios não o fazem seria querer imputar à realidade indígena o já esgotado debate entre modelo e realidade na antropologia do parentesco.

Os casamentos de primos cruzados bilaterais são o que se espera de um sistema dravidiano, pois é a forma mais comum de troca restrita e em vários casos caracteriza trocas de irmãs. Os casamentos patrilaterais, por sua vez, também podem ser entendidos como uma forma de troca restrita, porém diferida: no casamento patrilateral, uma mulher dada em uma geração é devolvida na geração seguinte, criando um ciclo curto de troca. Tanto a troca de irmãs quanto a troca patrilateral são o modelo geral da aliança nas terras baixas da América do Sul, onde prevalecem as formas de troca restrita (Viveiros de Castro e Fausto 1993). Mas salta aos olhos a quantidade de casamentos com a prima cruzada matrilateral entre os Kalapalo, que precisam ser compreendidos. Estes casamentos, como já mencionei, têm como característica não serem confundidos com casamentos de primos bilaterais (isto é, WM não se confunde com nenhuma mulher que recaia na categoria FZ).

\section{O CASAMENTO MATrilateral E a POLítica}

A terminologia kalapalo não assimila MBW a FZ de maneira alguma, o que abre a possibilidade da esposa de um tio materno ser qualquer mulher. Ao mesmo 
tempo, o irmão da mãe também é marcado de várias maneiras. Uma é através do comportamento, pois, apesar das relações entre tio e sobrinho serem bastante relaxadas, o irmão da mãe deve ser alvo de mais respeito e vergonha ${ }^{23}$ do que um irmão ou irmã do pai. A proximidade que o irmão da mãe guarda com a afinidade faz com que o comportamento perante ele oscile entre uma jocosidade permitida entre parentes próximos e a vergonha/respeito que se deve ter dos afins. Além disso, o casamento com a MBD frequentemente apareceu como uma preferência no discurso dos meus interlocutores. É comum ouvir afirmações do tipo « o certo mesmo é o tio $[a w a]$ dar a filha pro sobrinho », e quando se pergunta a um homem kalapalo a razão dele ter se casado com uma determinada mulher, a relação de filha do tio materno tende a ser a primeira a ser evocada, mesmo quando a mulher em questão for uma prima cruzada bilateral.

De fato, parece haver uma hierarquia entre o cálculo uterino e o paterno na escolha dos vocativos, pois de maneira geral os termos apropriados de parentesco traçados pela linha materna são preferidos em relação aqueles traçados pela linha paterna (para mais detalhes, ver Guerreiro Júnior 2008, p. 113). Isto ficou muito claro para mim enquanto investigava as relações entre pessoas que pareciam ter se casado com parentes paralelos. Eram homens casados com $\mathrm{FBD}$ ou $\mathrm{F} \widehat{\mathrm{BXD}}$, mulheres que pelos cálculos iroqueses (eu achava) seriam estranhamente classificadas como suas irmãs. Mas meus interlocutores sugeriram que eu deixasse de lado o parentesco (paralelo) pela linha paterna e me chamaram a atenção para a importância de se « pensar pela mãe » (como um de meus principais interlocutores insistiu um dia, após ter de responder mais de uma dezena de dúvidas minhas, certamente esperando que se eu acatasse sua sugestão talvez não lhe importunasse mais com aquele tipo de coisa). Quando comecei a «pensar pela mãe» vi que aqueles estranhos casamentos entre «parentes paralelos » que eu investigava eram na verdade entendidos pelos homens kalapalo como casamentos com a MBD - eu apenas não dispunha das informações minimamente necessárias. Certamente haveria a possibilidade inversa: pessoas que se casaram com parentes paralelos do lado materno mas que são parentes cruzados do lado paterno. Contudo, apesar desta ser uma possibilidade lógica não registrei nenhum caso desse tipo durante minha pesquisa.

Um de meus interlocutores também associou o casamento com a filha do tio materno às práticas matrimoniais dos ancestrais dos kalapalo e ao noivado. Segundo ele, « antigamente as pessoas se casavam com suas primas de verdade, os tios davam as filhas pros sobrinhos e todos ficavam noivos ». Esta ideia de que « antigamente era assim » não deve ser entendida em sentido literal-histórico, mas deve ser levada a sério quando pensada no contexto da cosmologia alto-xinguana. Pois, como já sugeriu Viveiros de Castro (1977, passim), a noção de que no passado tudo era perfeito e que o presente é uma forma degenerada do passado é algo corrente no pensamento dos povos da região, e os seres e práticas 
do passado distante possuem na cosmologia xinguana o valor de modelos, arquétipos. Aqui a relação $\mathrm{MB} / \mathrm{ZS}$ aparece como modelo da relação de afinidade, assim como a MBD aparece como o modelo de cônjuge feminino.

A menção do interlocutor aos noivados é fundamental, pois chama a atenção para a marcação do tio materno na realização de casamentos arranjados. Ao analisar esta prática, Basso (1973a, p. 90) apenas afirma que " the marriage proposal is made most often by the boy's parents to the relatives of the girl ", mas não dá mais detalhes sobre o arranjo. Entretanto, a norma para se arranjar um casamento é que isto seja feito entre a mãe do noivo e o pai da noiva, idealmente irmãos ou primos cruzados. Ou seja, o arranjo matrimonial deve ser feito por um par Z/B para seus filhos que são, um para o outro, MBD e FZS. Ao invés do noivado ser a forma canônica do casamento entre primos cruzados bilaterais, como já se sugeriu (Coelho de Souza 1995), para os Kalapalo ele é a forma ideal de realizar um casamento matrilateral.

E este é o único tipo de união entre os Kalapalo que exige o pagamento de bride wealth, além do bride service usual ${ }^{24}$ : no momento da mudança da rede do noivo para a casa da noiva (ato que marca o casamento), esta é buscada pelos parentes masculinos da mãe da noiva (seus irmãos e primos próximos), os quais devem receber da mãe do noivo colares de concha de caramujo, objetos bastante valiosos em todo o Alto Xingu, como pagamento (ihipügü); algum tempo após o casamento, o noivo deve presentear seu sogro (seu tio materno), por intermédio de sua mãe ou de sua esposa, com um colar de placas de concha de caramujo (inhu aketühügü), também considerado pagamento pela noiva. Ele deveria também presentear sua sogra com um pente (handa), mas que é um presente menos necessário do que o pagamento para o tio materno-sogro, e poucos efetivamente o fazem. Esta exclusividade do bride wealth neste tipo de casamento é significativa, pois evoca a observação de Leach (1951) de que, de modo geral, em sistemas de casamento matrilateral a circulação de riquezas se dá no sentido contrário ao das mulheres, além de evocar o comentário de Lévi-Strauss (2003, p. 495) sobre a recorrência de pagamentos aos parentes masculinos da mãe da noiva em sistemas com casamento deste tipo.

Como explicar esta ideologia matrilateral dos Kalapalo, em consonância com a marcação da figura do tio materno no comportamento, na hierarquia do cálculo uterino sobre o cálculo paterno e nos casamentos arranjados? Os casamentos com a MBD somam uma quantidade muito grande de uniões (pouco mais de $50 \%$ dos casamentos analisados) e são o próprio modelo ideal de casamento para os Kalapalo. Este tipo de união existe para os Kalapalo como um valor positivo (e, note-se, uma das poucas disposições positivas sobre o casamento que eles fazem), o que me faz pensar que tais casamentos certamente devem poder ser integrados de forma lógica à estrutura do sistema de aliança. Uma hipótese que me parece plausível, apesar de especulativa, talvez possa ser encontrada em algumas relações entre o parentesco, a chefia e o regionalismo, tal 
como encontradas em algumas narrativas e através do que pode ser observado por estatísticas mais detalhadas destas uniões.

A figura do tio materno e a relação de afinidade entre $\mathrm{MB} / \mathrm{ZS}$ é bastante marcada em algumas narrativas kalapalo. Por exemplo, ela é a relação central do mito de origem da humanidade: ao se ver ameaçado pelo Onça (Enitsuẽgü), chefe da aldeia das onças, e com medo de ser devorado, o demiurgo Kuatüngü se refere a ele como « meu sobrinho » (uhatuün, ZS) e lhe oferece em casamento suas filhas. No mito de origem do fogo, uma relação análoga aparece entre o Urubu-Rei (Uguhu Kuẽgü), chefe da aldeia dos pássaros, e Taũgi. Para obter o fogo, propriedade do Urubu-Rei, Taũgi o sequestra; com medo, o chefe dos pássaros e dono do fogo também se refere a Taũgi como «meu sobrinho » e lhe dá uma esposa, que vai viver com ele em sua aldeia.

Em ambas estas narrativas, o medo entre dois seres diferentes, os grandes chefes de suas respectivas aldeias, faz com que aquele que se sente ameaçado se refira ao outro como sobrinho uterino e doe mulheres a ele no intuito de pacificá-lo. Em ambos os casos, o conflito é iminente, mas é substituído pela troca assimétrica (a doação de uma filha por um MB para seu ZS) e pela afinidade, que alteram o rumo dos acontecimentos e tornam as relações entre os seres produtivas para os humanos. Ao invés da morte possível, nos dois casos acima os grandes chefes pacificam seus inimigos doando mulheres a eles. Em outra narrativa, na qual não há o perigo da guerra, ainda assim encontramos a associação entre um casamento matrilateral do jovem chefe da aldeia dos Macucos e a filha do chefe da aldeia Igihagahitu: o jovem anetü Macuco procura uma esposa e chega à conclusão de que não haveria ninguém melhor do que a filha de seu tio materno, chefe de Igihagahitu. O modelo da relação nestas três narrativas é como representado no diagrama abaixo (Figura 4):
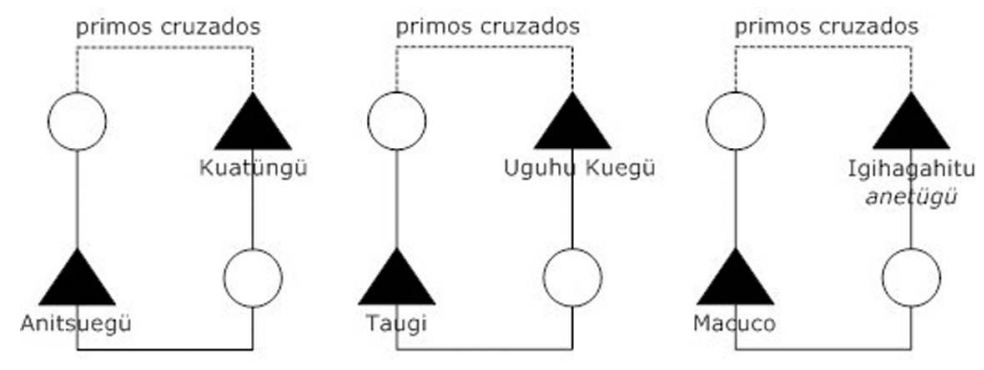

chefes principais de aldeias diferentes

FIG. 4 - Diagrama que representa as relações de afinidade entre MB e ZS em algumas narrativas kalapalo. 
Em outra narrativa, que é uma espécie de mito sobre a origem política da sociedade regional alto-xinguana, os Kalapalo contam uma história sobre a divisão de uma grande aldeia na qual supostamente todos os povos xinguanos teriam vivido juntos. Kalapalo, Matipu, Nahukuá, Wauja, Mehináku e Yawalapíti ainda não existiam como tais, mas apenas seus ancestrais muito antigos, falando cada um a sua língua mas vivendo juntos na antiga aldeia Kuakutu ${ }^{25}$ sob a liderança do chefe Aküana. Após a divisão da aldeia por problemas com inimigos invasores, Aküana resolveu ficar na aldeia com sua parentela, mas fez questão de ir até a nova aldeia trazer sua noiva para Kuakutu, filha de Hema, seu tio materno e que se tornara chefe do novo agrupamento. Novamente tem-se o mesmo modelo das narrativas anteriores: dois grandes chefes, duas aldeias e um casamento com a MBD com residência virilocal.

O que estas narrativas têm em comum? Em primeiro lugar, o fato de que as pessoas envolvidas em relações de afinidade são anetaõ de aldeias diferentes. Em segundo lugar, a residência do casal em todos os casos é virilocal (contrariamente ao padrão uxorilocal) o que é uma prática comum entre os chefes, sobretudo os mais importantes, que evitam ficar sob o mesmo teto de seus afins doadores e trazem as esposas para residir consigo.

Nestas narrativas, o casamento com a MBD é endogâmico do ponto de vista do status dos parceiros envolvidos (entre chefes e filhas de chefes), mas exogâmico do ponto de vista da origem dos cônjuges, que moram em aldeias diferentes (não nos esqueçamos que, no plano de existência onde se passam estas narrativas, são todos humanos). É possível notar que esta «endogamia de status » entre os principais nobres associada à exogamia de grupo local existe de fato. Observando os casamentos matrilaterais registrados em Aiha, percebe-se que $85 \%$ destas uniões (23 casamentos) foram realizadas entre filhos ou sobrinhos próximos (isto é, de primeiro grau ou co-residentes) de chefes e chefas, com mulheres classificadas como MBD que são, por sua vez, filhas ou sobrinhas próximas de chefes e chefas. Ou seja, a grande maioria dos casamentos matrilaterais registrados é entre nobres. Ainda, $52 \%$ (12) destes casamentos de nobres é entre homens e mulheres originários de diferentes aldeias, e todos estes são entre homens que exercem ativamente a função de anetü e mulheres que também exercem ativamente o papel de itankgo (Figura 5). Note-se o contraste com os casamentos de não-chefes: deles, apenas três são localmente exogâmicos. Na monografia de Viveiros de Castro (1977, p. 68) sobre os Yawalapíti também é possível notar, a partir de uma breve genealogia dos chefes apresentada pelo autor, que os principais chefes das últimas três gerações (ancestrais em linha paterna do chefe atual) haviam se casado com primas cruzadas matrilaterais, apesar da preferência pelo casamento de primos cruzados bilaterais e a troca de irmãs. 


\begin{tabular}{|c|c|c|}
\hline Tipos de uniões de nobres com a MBD & Total & Percentual \\
\hline Localmente exogâmicos & 12 & $52 \%$ \\
\hline Localmente endogâmicos & 11 & $48 \%$ \\
\hline Total & 23 & $100 \%$ \\
\hline
\end{tabular}

FIG. 5 - Diagrama mostrando os tipos de casamentos envolvendo nobres.

Junto a isto, há outro dado interessante que diz respeito aos únicos quatro casamentos entre primos de primeiro grau que pude registrar: todos são casamentos com primas cruzadas matrilaterais; três deles ocorreram entre pessoas residentes em aldeias diferentes (dos quais dois são entre chefes importantes) e um deles, o único realizado entre co-residentes, é entre um dos principais chefes da aldeia Tanguro e duas itankgo. Nestas condições, me parece que o casamento matrilateral pode ser associado em parte a casamentos (idealmente) localmente exogâmicos e entre pessoas em posições superiores na hierarquia social alto-xinguana. Esta é uma situação que se repete em vários casamentos matrilaterais, sugerindo que de fato o casamento com a MBD seja uma preferência das parentelas dos chefes, acrescida da preferência pelo casamento localmente exogâmico e virilocal (sobretudo quando se trata dos chefes principais - os " primeiros caciques »).

Vejamos a situação dos três principais chefes de Aiha. Waya, o chefe principal, casou-se com uma itankgo filha de seu tio materno Sagama, chefe dos Angaguhütü, reduzidos atualmente a apenas dois sobreviventes que vivem em Aiha ${ }^{26}$. Apesar de ser um casamento localmente endogâmico, é interessante que tenha ocorrido entre filhos dos mais importantes chefes de dois grupos. Hagema, o segundo anetü na hierarquia de Aiha, também casou-se com uma MBD, uma itankgo filha de um dos chefes dos Yawalapiti (de fato, um primo paralelo de Aritana, o chefe principal), e um de seus filhos também se casou com uma filha de um irmão de sua mãe na aldeia yawalapiti. $\mathrm{O}$ 《 terceiro cacique» kalapalo, Tühoni, também é casado com duas MBD, duas itankgo, filhas da chefe (desde que seu marido morreu) dos Kalapalo que moram no PIV Kuluene. Da mesma forma como encontramos nas narrativas, vemos pelo menos dois dos três principais chefes de Aiha envolvidos em casamentos matrilaterais, virilocais e localmente exogâmicos. Um deles, se não é localmente exogâmico em sentido pleno, é entre chefes de grupos distintos (Figura 6): 

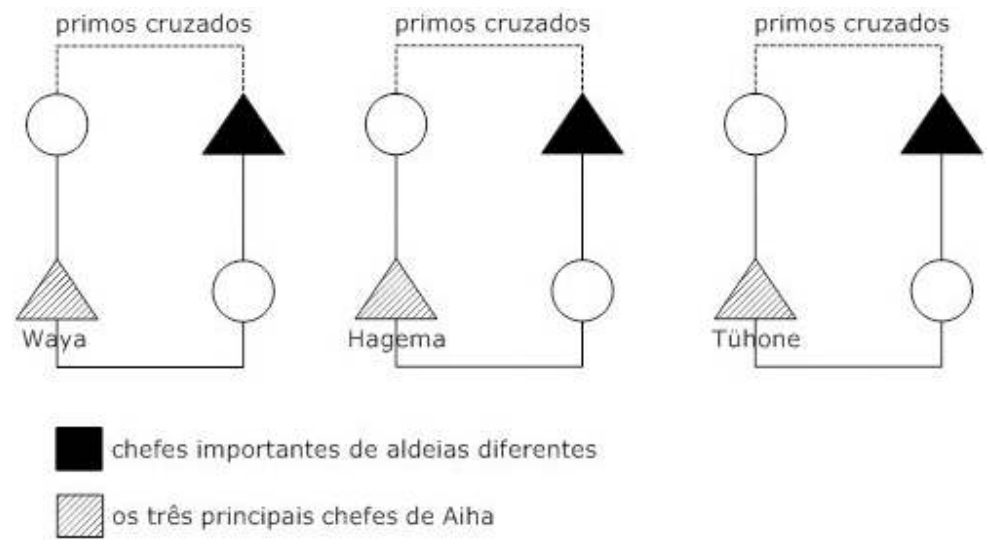

FIG. 6 - Diagrama mostrando as relações de aliança dos três principais chefes de Aiha.

Menget $(1978 ; 1985 ; 2001)$ afirma que o sistema político xinguano oscila entre um ideal de aliança simétrica e a « anti-aliança de fato », referindo-se à existência simultânea da idealização do casamento de primos cruzados bilaterais com a prática frequente do sequestro de mulheres. A primeira forneceria as bases da aliança pacífica entre parentelas e mesmo entre grupos inteiros, enquanto a segunda marcaria a violência característica da região e expressaria um desejo de evitar as obrigações e a hierarquia inseparáveis da afinidade. Proponho que a prática do casamento matrilateral, virilocal e exogâmico pelos chefes kalapalo seja vista como uma transformação (no sentido de Lévi-Strauss) desta « antialiança », dado que se trata de uma prática entre afins potenciais que « dribla » as obrigações e assimetrias decorrentes da afinidade efetiva.

Os chefes alto-xinguanos frequentemente se classificam como primos cruzados, independentemente de suas relações genealógicas, tanto nos mitos quanto atualmente (ou seja, se vêem como afins potenciais). Ao preferirem o casamento com uma MBD de outra aldeia, eles se colocam na posição de receptores de esposas, mas na condição peculiar de não se submeterem prolongadamente (ou mesmo nunca) ao trabalho e à vergonha devida a seus afins doadores, o que é garantido pela residência virilocal. Ao tomar mulheres de seus afins potenciais por status (outros nobres) e negar sua submissão à hierarquia produzida pela dívida, os chefes kalapalo se colocam na posição de anti-afins: recebem mulheres de alto status de fora do grupo local, negando tanto a troca simétrica efetiva com o "exterior » quanto as possíveis consequências da troca assimétrica.

A situação dos homens casados com MBD no interior do grupo local é indissociável desta tentativa de fuga da « afinidade » empreendida pelos chefes de 
status superior. Ao observarmos estes casos, vemos que se trata na maioria de homens casados com mulheres da parentela do chefe principal de Aiha. Alguns destes homens também possuem o título de anetü, mas ocupam posições inferiores na hierarquia e devem muita vergonha ao chefe principal, seu afim doador. Esta imagem do "chefe como afim » também aparece na mitologia, como no mito de origem da aldeia à qual os Kalapalo remetem sua origem mais próxima (Kuapügü). Os Kalapalo desejavam realizar o ritual undühe, e para isso foram buscar em outra aldeia um de seus chefes, que era um grande cantor, pois havia aprendido as músicas daquele ritual diretamente com o homem que as trouxe da aldeia do Peixe-Cachorra (Ahi Kuẽgü), o chefe dos peixes. Este homem foi até a aldeia kalapalo, cantou durante três dias seguidos e o ritual foi um sucesso. O sucesso foi tão grande que os chefes de Kuapügü se reuniram em público no centro da aldeia e decidiram convencer o homem a deixar sua aldeia para vir morar com eles, onde ele poderia vir e se tornar um chefe. Mas havia uma condição para tanto: que ele trouxesse consigo sua filha, uma jovem que estava no período de reclusão pubertária.

Acredito que esta última narrativa, na qual um homem se torna chefe em outra aldeia trazendo sua filha reclusa, pode elucidar os casamentos dentro do grupo local e a prática do noivado. É recorrente em Aiha a ideia de que «pra casar com filha de cacique é preciso pagar »-o que remete ao noivado, única forma de casamento que envolve bride wealth. Como eu havia dito anteriormente, estes casamentos devem ser arranjados por uma mulher e um homem que possam se classificar como um par Z/B, o que implica no casamento de um homem com uma MBD. Se este é o modelo para o casamento com a filha de um chefe, isto significa que idealmente estas mulheres devem se casar com seus FZS, para os quais elas são, respectivamente, MBD. Ou seja, mulheres nobres que se casem em sua aldeia de origem idealmente se casam com homens em posição hierarquicamente inferior em relação a seus pais e irmãos. Em Aiha, a prática do noivado caiu em desuso, mas o ideal de noivado com a filha de um nobre que seja ao mesmo tempo uma prima cruzada matrilateral permanece ao menos como modelo consciente, elaborado pelas pessoas quando se fala no casamento com a filha de um anetü. De fato, dos únicos cinco homens que ficaram noivos em Aiha, quatro se casaram com uma MBD, e apenas um se casou com uma FZD. E recentemente minha hipótese ganhou subsídios: um jovem, filho de uma itankgo importante, irmã do chefe principal, está noivo de sua MBD, filha de um anetü da aldeia Tanguro. Também, um dos três principais chefes de Aiha havia saído da aldeia para criar seu próprio grupo local, e muito rapidamente arranjou um casamento entre sua filha mais nova e o filho de uma de suas primas cruzadas que vive em outra aldeia.

Esta situação contrasta radicalmente com a que serve de base para a hipótese clastreana sobre o chefe ameríndio como " prisioneiro do grupo » através da poligamia (Clastres 2003). Pois, ao invés de ser um prisioneiro do grupo através 
da dívida provocada pela afinidade, o chefe kalapalo, do ponto de vista de seu grupo local, é um doador de esposas: para se casar com uma nobre, ela deve ser uma MBD e é preciso reunir bride wealth. Durante meu período de pesquisa de campo o grupo de germanos ao qual pertence o chefe principal era aquele que mais dispunha de mulheres casadas com seus F $q$ XS (=FZS) no interior da aldeia. Dos 14 casamentos matrilaterais localmente endogâmicos (incluindo nobres e « comuns »), 6 são com mulheres de um mesmo grupo de germanos composto por filhas ou sobrinhas de primeiro grau do chefe principal e outros 3 são com mulheres do grupo de germanos do chefe principal (uma irmã e duas de suas primas cruzadas). Ou seja, dos 14 homens casados com primas cruzadas matrilaterais de Aiha, 9 deles receberam mulheres de uma mesma parentela próxima (a parentela do chefe principal). Todo este grupo de germanos se encontra exclusivamente na posição de doador de mulheres em relação a alguns homens que, em relação à assimetria da dívida produzida pelo casamento matrilateral, são afins em posição inferior em relação a todo este grupo de germanos (de onde saiu o chefe principal) e inferiores também em relação a seus cunhados (de onde deverá sair o próximo chefe principal). Esta distinção, fundada sobre a dívida de uma esposa, é expressa pela diferença de vergonha (ihütisu) entre afins, categoria que funciona como um operador lógico das relações hierárquicas no campo do parentesco. Tal distinção hierárquica se deixa perceber no sistema de atitudes, na etiqueta do comportamento e do «bom falar » kalapalo, no qual afins em posição inferior tratam seus afins superiores (sejam eles seus cunhados ou seus sogros) com muita deferência, diferentemente do que podem fazer cunhados em posição simétrica (em relação de troca de irmãs, por exemplo).

Desta forma, tem-se uma rede de alianças assimétricas entre a parentela do principal chefe e outras pessoas. A figura do « chefe receptor » e aprisionado pela afinidade de seus afins doadores em relação ao grupo local não se aplica aos chefes kalapalo: eles, pelo contrário, encarnam a figura do chefe doador, o grande afim de seus sobrinhos uterinos. Os principais nobres kalapalo procuram sempre receber mulheres de fora da aldeia, evitando a relação de afinidade com seus sogros e cunhados doadores, e doam mulheres a seus sobrinhos uterinos, a maioria deles filhos de nobres de status inferior. As mulheres da parentela de um chefe podem se casar com pessoas abaixo delas na hierarquia, mas nunca acima - é isso que significa dizer que casar com a filha de um chefe exige pagamento, pois é o casamento com uma MBD. Quando se casam com pessoas julgadas de status equivalentes (como os filhos dos principais chefes), a aliança tende a se realizar entre pessoas que não residem na mesma aldeia.

A partir destas informações é possível sugerir que, enquanto as formas da troca restrita predominam entre as pessoas comuns e constituem majoritariamente casamentos no interior do grupo local, o casamento matrilateral é uma preferência dos nobres, e aqueles realizados pelos chefes mais importantes se dão 
sobretudo entre anetaõ e itankgo de grupos distintos. Primeiramente, há uma tendência dos principais chefes tomarem mulheres, MBD, de outros grupos locais (Figura 7):

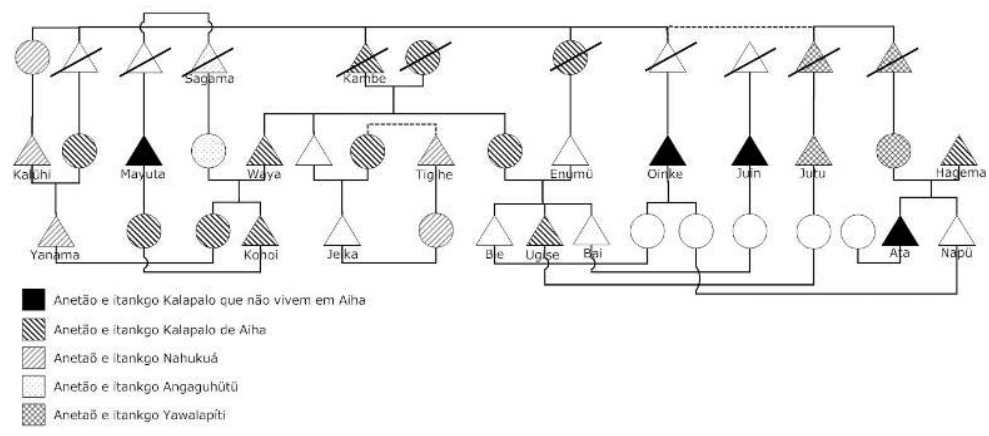

FIG. 7 - Recorte de uma rede de alianças entre anetaõ e itankgo kalapalo e de outros grupos.

Nestas relações os homens ficaram isentos da residência uxorilocal, e nota-se uma grande articulação entre as principais parentelas de chefes de grupos que se consideram bastante "próximos" (seja pela língua falada, por relações de parentesco ou por relações rituais). Ainda, os chefes tendem a casar suas filhas com seus ZS, se colocando na posição de doadores de esposas em relação a outros homens de seu grupo local, que em sua maioria também são filhos de nobres de status inferior (Figura 8):

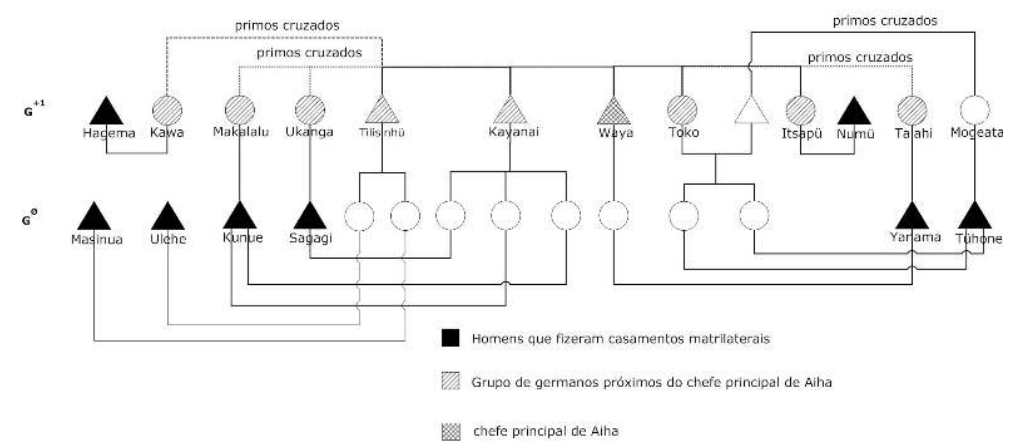

FIG. 8 - Representação da hipogamia das mulheres da parentela do primeiro cacique de Aiha. Note-se que, além dos outros dois chefes principais (Hagema e Tühone), que fizeram casamentos matrilaterais localmente exogâmicos, os outros são anetão menos importantes que fizeram casamentos localmente endogâmicos. 
E, dada a multiplicidade de afins potenciais, não encontra-se nada parecido com « ciclos », mas sim diversas soluções locais que utilizam a forma matrilateral. O próprio Leach (1951) já havia demonstrado para os Kachin que a ideia de que o casamento matrilateral implicaria em ciclos é uma falsa dedução, pois entre eles mesmos a diferença entre linhagens doadoras e receptoras de esposas só faz sentido no nível local.

Assim, acredito ser plausível adotar a hipótese de que o casamento matrilateral está diretamente relacionado à hierarquia política e ao regionalismo: no interior da aldeia o casamento matri pode favorecer a posição hierárquica de um chefe ou de toda uma parentela próxima, enquanto no exterior estes casamentos produzem uma grande conexão entre as parentelas de chefes. Se a troca restrita inclusiva existe e explica cerca de metade das uniões no interior de Aiha, a troca matrilateral talvez seja uma estrutura que a englobe, pois está relacionada diretamente ao sistema político em seu sentido amplo: ligando hierarquicamente chefes no interior de uma mesma aldeia e ligando simetricamente (por causa da residência virilocal) os principais chefes de aldeias distintas. E lembremos que a existência política de uma aldeia, o seu reconhecimento como uma aldeia de verdade, sua capacidade de realizar rituais e participar do sistema regional de maneira autônoma, depende da existência de ao menos um grande chefe verdadeiro (anetü hekugu). Não é à toa que o mundo humano começa com uma relação de afinidade potencial transformada em afinidade efetiva entre tio materno e sobrinho uterino e que este modelo reaparece constantemente na mitologia. E como me disse uma vez um kalapalo, " pode casar com quem quiser, mas filha de cacique tem que pagar».

É no paralelismo das oposições entre «troca restrita inclusiva » e «troca assimétrica » e « casamentos de comuns » e « casamentos de nobres » que parece ser possível encontrar uma resposta para o lugar do casamento matrilateral no sistema kalapalo. Poderíamos correlacionar as duas principais modalidades de aliança em Aiha da seguinte forma (Figura 9):

\begin{tabular}{|c|c|}
\hline Nobres & Comuns \\
\hline Endogamia de parentela/substância & Exogamia de parentela \\
\hline Exogamia de grupo local & Endogamia de grupo local \\
\hline Casamento matrilateral & Troca restrita inclusiva \\
\hline
\end{tabular}

FIG. 9 - Representação das características da dualidade de regimes matrimoniais entre nobres e pessoas comuns. 


\section{CONSIDERAÇÕES FINAIS}

De acordo com Viveiros de Castro e Fausto (1993, p. 155), os sistemas multibilaterais forneceriam as bases da organização social da maioria dos povos amazônicos, pois sua estrutura fundada na existência de múltiplos ciclos locais de troca restrita permitiria compreender várias das características das sociedades amazônicas assinaladas por inúmeros autores: seu " atomismo », a baixa ênfase na elaboração da organização social no espaço, o igualitarismo, a incapacidade do parentesco de operar como mecanismo de totalização do sócius e a própria falta de noção de «totalidade » característica destas sociedades. "Le schéma ternaire discontinu patrilatéral apparaît comme la solution la plus naturelle pour un système d'unités multiples et équistatutaires liées par l'echange restreint ».

Mas estas características clássicas expressas pela literatura dos povos amazônicos não coincidem exatamente com o que se observa entre os povos alto-xinguanos. Ao invés de se organizar a partir de grupos pequenos, com pouca elaboração da organização social no espaço e igualitários, os Kalapalo e seus vizinhos se organizam idealmente em grandes grupos e em aldeias circulares que refletem na oposição entre centro e periferia um dado básico da organização social: a hierarquia entre chefes e comuns. Esta diferença na organização social tem como contrapartida uma distinção entre a aliança nos sistemas de povos amazônicos mais clássicos [como os próprios grupos karib das Guianas, de onde teriam migrado os ancestrais dos Kalapalo (Heckenberger 2001)] e a aliança entre os Kalapalo: a hierarquia dos chefes parece coincidir com um princípio de troca assimétrica, através do casamento com a prima cruzada matrilateral.

A razão pela qual os Kalapalo imaginam as relações entre os chefes através do modelo matrilateral é algo que não parece possível responder sem empreender uma pesquisa comparativa entre as parentelas dos chefes de outras aldeias nas quais os Kalapalo realizam alianças. Pois estas talvez pudessem ser realizadas através do modelo da troca restrita inclusiva, mas que parece não ser o ideal kalapalo para tanto: o casamento assimétrico entre filhos de chefes de aldeias distintas, realizado de acordo com a linguagem do casamento com a prima cruzada matrilateral, é idealizado nos mitos e preferido na prática. É uma constatação que destoa do que se sabe sobre os casamentos dos chefes kamayurá, por exemplo (ver Bastos 1990), que aparentemente praticam uma endogamia de status através do casamento com a ZD.

Os próprios Kalapalo afirmam que os chefes Kamayurá se casam frequentemente com sobrinhas próximas, prática abominada pelos Kalapalo [os Trumai também teriam dito a Quain (Murphy et Quain 1955, p. 52) que reprovavam a prática do avunculato pelos Kamayurá]. Ao mesmo tempo, eles também interpretam seus ideais matrimoniais à luz das práticas e ideais matrimoniais de um de seus vizinhos aruak, que afirmam que o povo que mais 
arranja casamentos de noivos e no qual os homens mais se casam com as filhas dos irmãos de suas mães seriam os Mehináku.

Apesar dos rumos tomados pelas discussões sobre complexidade (Héritier 1981; Viveiros de Castro 1993b, 1998; Houseman e White 1996), é tentador retomar um ponto pouco lembrado da definição original de Lévi-Strauss das estruturas complexas: por um lado, estas estruturas seriam aquelas que não permitem identificar o cônjuge pela terminologia e, por outro, são aquelas que podem ser pensadas como estruturas nas quais a troca restrita e a troca generalizada se combinam de maneiras diversas (Lévi-Strauss 2003, p. 506), de modo que a prática de um ou outro tipo depende de questões extrínsecas ao parentesco (tais como fatores estéticos, políticos, econômicos, religiosos, entre outros). Parece ser uma definição interessante para se ver o caso Kalapalo. Mas ao invés de " extrínseco » (o que me traz uma imagem muito sistêmica e compartimentada do social) penso que deve valer a pena pensar a aliança assimétrica e a assimetria política aqui como "ordens constitutivas de tipo provisório », como diz Strathern (1985) sobre o parentesco e a economia. Isto é, que são inseparáveis, se produzem reciprocamente através de analogias, traduções e adaptações - mas cuja separação (analítica) mantém um valor heurístico para o antropólogo. Pois não é infrequente a associação entre hierarquia e casamento matrilateral, uma discussão já clássica na antropologia do parentesco (Leach 1951; Lévi-Strauss 2003). Ao invés de pensar estes dois fenômenos separados e em eventuais relações funcionais, como sempre se corre o risco de fazer, é importante entender estes dois fenômenos como duas atualizações das ideias indígenas de assimetria. Em contextos nos quais as redes de aliança dificilmente podem ser pensadas a partir de conceitos que tenham como pré-suposto alguma ideia reificada da sociedade como totalidade, talvez prestar atenção nesta correlação analógico-constitutiva entre casamento matrilateral e chefia (ou, ainda, assimetria matrimonial e assimetria política), possa ser um exercício produtivo, na medida em que, sendo nestes casos o casamento um campo que não pode ser isolado da política, o estudo do lugar onde eles coincidem deve permitir à análise passar de um a outro e, ainda, passar de ambos a outros fatos relativos à produção das socialidades indígenas.

$\mathrm{O}$ casamento matrilateral entre os Kalapalo também faz remeter à metáfora utilizada por Lévi-Strauss (1986, p. 186) para se referir ao casamento nas sociétés à maisons, onde as mulheres seriam simultaneamente « a ponte e a prancha »: as mulheres circulariam não dentro de uma estrutura de e para a troca de mulheres (o que seria uma forma possível de se definir uma estrutura elementar), mas estariam sempre sobrepostas à circulação ou manutenção de bens e títulos de prestígio. Em sociedades de casas, onde alguma propriedade material ou imaterial deve permanecer no grupo (no caso kalapalo, a condição de nobres), algumas instituições intervêm na síntese de princípios antagônicos, como troca simétrica/troca assimétrica, e, frequentemente, simetria/assimetria política. 
A frequente associação entre casamento matrilateral e chefia em alguns sistemas que, fora do campo da chefia, apresentam casamento com a filha da irmã do pai ou equivalentes [poderíamos citar as ilhas Trobriand (Powell 1960; 1969), os Haida do noroeste americano (Murdock 1934), ou mesmo os Kalapalo do ponto de vista da estatística de casamento dos não-anetaõ], se assemelha a práticas que marcam as tais sociedades de casas. Talvez seja o caso de se levar mais adiante o uso do modelo das casas no Alto Xingu, como já sugerido por Heckenberger (2005, pp. 255-290).

Se tais associações são válidas, só pesquisas futuras poderão confirmar, e ainda resta muito a investigar: as relações entre as alianças e a formação de novas aldeias; as implicações das alianças entre famílias de chefes no sistema ritual; e, obviamente, a aliança em outros grupos xinguanos. Certamente o estudo da aliança entre outros grupos da região permitirá no futuro uma compreensão melhor do lugar dos sistemas complexos de aliança na América do Sul e do lugar ocupado pelos casamentos na constituição do sistema político alto-xinguano. *

* Manuscrit reçu en février 2009, accepté pour publication en janvier 2011.

\section{NOTAS}

1. Este artigo sintetiza o argumento central desenvolvido na minha dissertação de mestrado, defendida junto ao Programa de Pós-Graduação em Ciências Sociais da Universidade Federal de São Carlos (PPGCSo/UFSCar, São Paulo, Brasil). A pesquisa que deu origem a este trabalho foi realizada no bojo do projeto « Sistemas terapêuticos indígenas e a interface com o modelo de atenção à saúde: diferenciação, controle social e dinâmica sócio-cultural no contexto alto xinguano » (Cardoso 2005), coordenado pela Prof. Dra. Marina D. Cardoso e financiado pelo CNPq. Agradeço a Edmundo Peggion, Marcio Silva, Marcos Lanna, Marina Cardoso e Marina Novo pelas críticas, sugestões e pela infinita ajuda que recebi de todos ao longo do trabalho. Agradeço também a Carlos Fausto, pela leitura cuidadosa e pelos comentários detalhados de versões anteriores deste artigo. Os equívocos e imprudências são, claro, de minha inteira responsabilidade.

2. Com isto quero dizer que a oposição entre humanos e não-humanos, tal como a modernidade construiu em torno da distinção entre homem (ou cultura) e natureza, não é pertinente entre os coletivos ameríndios. Para discussões mais detalhes ver Lima (2005) e Viveiros de Castro (2002b).

3. Por exemplo, no hagaka, a festa de antagonismo entre primos cruzados, as mulheres do grupo anfitrião dançam com os homens dos grupos convidados e vice-versa, oferecendo uma imagem interessante da aliança simétrica. Já a aliança assimétrica aparece no mito de origem, no clássico episódio no qual o demiurgo Kuatüngü oferece suas filhas ao chefe das onças a fim de acalmá-lo.

4. Para uma discussão sobre como o casamento com a FZD pode ser visto como uma forma de troca restrita e simétrica, ver Viveiros de Castro e Fausto (1993).

5. Assim como outros autores (Barcelos Neto 2003; Viveiros de Castro 1977), utilizo o termo «nobres» porque ele permite fazer referência a todos que descendem de chefes, mas que não necessariamente possuem o título de anetü (para homens) ou itankgo (para mulheres).

6. Todos os karib xinguanos chamam estas pessoas de anetü. Os Yawalapíti as chamam de amulaw, os Wauja e Mehináku de amunaw, os Kamayurá de morerekwat, os Aweti de morekwat.

7. A expressão «substância nobre» foi cunhada por Barcelos Neto (2008) para se referir à condição diferenciada não só dos chefes « executivos » (que usam ativamente o título de anetü), mas de 
seus parentes em geral (a «nobreza »). Contudo, é difícil identificar se há de fato algo como uma « substância » no sentido geralmente utilizado pelos americanistas (como quando se fala dos papéis do sangue e do sêmem como substâncias formadoras da pessoa, por exemplo). Os Kalapalo se referem ao sangue como substância responsável pela transmissão da condição de nobre, e ele me parece que pode ser chamado assim em um sentido dado por Strathern (1999) ao termo: uma objetificação de relações que compõem a pessoa. Por isso penso que se lermos a noção de substância nobre de Barcelos Neto a partir das considerações dos Kalapalo e de Strathern, esse conceito pode ser útil para descrever a situação etnográfica, ao menos provisioriamente.

8. Para designar as posições de parentesco utilizo a grafia inglesa, segundo a qual se deve ler os marcadores dos kintypes da esquerda para a direita. As posições são formadas pela primeira letra do termo de parentesco em inglês $(\mathrm{F}=$ father, $\mathrm{M}=$ mother, $\mathrm{B}=$ brother, $\mathrm{S}=$ son, $\mathrm{D}=$ daughter, $\mathrm{Ch}=$ children, $\mathrm{BD}=$ brother's daughter, FFBS=father's father's brother's son, etc.), à exceção do marcador para a posição de « irmã » $(\mathrm{Z}=$ sister $)$, que tem sua letra alterada para evitar confusão com a posição de « filho » $(\mathrm{S})$. O símbolo Ø indica que não há termo de parentesco para tal posição ou que não há outras posições definidas pelo mesmo termo. Quando utilizado à direita da letra « $G$ » ele marca a geração de referência. O marcador « $\mathrm{X}$ », por sua vez, é utilizado para se referir à posição genérica de « primo cruzado », sendo acompanhado do símbolo masculino ( $\delta$ ) ou feminino ( $q$ ) à sua esquerda indicando o sexo do indivíduo. As indicações geracionais são feitas a partir da letra $\mathrm{G}$ em maiúsculas acrescida do número da geração em sobre-texto (por exemplo, G+1, G-1, GØ, G+2, etc.). As abreviações m.f. e h.f. significam, respectivamente, « mulher falando » $\mathrm{e}$ « homem falando ».

9. Segundo Viveiros de Castro e Fausto (1990), tanto a troca de irmãs quanto o casamento de primos cruzados bilaterais seriam achatamentos geracionais da fórmula patrilateral.

10. Na Amazônia há pelo menos um caso deste gênero que é bastante conhecido, o dos Shuar (Taylor 1998).

11. Não há nenhum termo que designe de forma absoluta a categoria dos não-chefes, sempre definida em relação aos chefes de fato. Os anetaõ frequentemente se referem a essas pessoas como talokito, um termo pejorativo que significa « imprestável », « inútil », " fraco », « ineficaz », mas que não é usado abertamente. Fausto (comunicação pessoal), em uma leitura que fez de uma versão anterior deste artigo, nota que os Kuikuro se referem ao pessoal de um chefe (incluindo aqui chefes menos importantes) como sandagü ou itsamagagü, o que também é válido para os Kalapalo. A primeira é a forma possuída de anda, termo que os Kalapalo traduzem como " companheiro », mas que claramente indica uma relação assimétrica: um grande chefe pode dizer que outra pessoa de sua aldeia é seu anda, mas o inverso não é possível. De fato, quando se trata de descrever a relação entre dois ou mais chefes, os Kalapalo preferem utilizar o termo itaginhokongo, algo como « os que conversam », que evita colocar um chefe na posição desconfortável de anda de outro. Itsamagagü, por sua vez, é a forma possuída de kamaga, provavelmente uma corruptela de «camarada ». É interessante que os Kalapalo possuem uma narrativa de origem dessa palavra, associada à captura de um kagaiha feita por um antigo chefe, e atribuem a ele a disseminação do termo kamaga no Alto Xingu.

12. Da família karib há os Kalapalo, Kuikuro, Matipu, Nahukuá; da família aruak, os Yawalapíti, Mehináku e Wauja; da família tupi-guarani, os Kamayurá; do tronco tupi, os Aweti; e, falando uma língua considerada isolada, os Trumai.

13. Na introdução a qualquer trabalho sobre o Alto Xingu a tríade « casamento, ritual e economia » aparece como conjunto distintivo e integrador dos alto-xinguanos em oposição àqueles que eles chamam de « índios bravos » (ngikogo, em karib kalapalo). Acrescentei a feitiçaria à lista porque ela também é um elemento de distinção xinguana (pois acusações não se dirigem a índios não-xinguanos) e, ao mesmo tempo, um elemento de produção de relações regionais pacíficas e de diferenciação (Coelho de Souza 2001).

14. Aiha e Tanguro. Realizei minha pesquisa de campo em Aiha, a principal aldeia kalapalo, durante 12 meses intercalados entre 2006 e 2010, mas o material que utilizo aqui envolve relações com pessoas de outras aldeias kalapalo e das aldeias Nahukuá, Yawalapiti, Matipu, Kuikuro e Kamayurá. 
15. Tehu hungu, Tahoki, Ajuaga Hotagü, Taũgi Hotepügü, PIV Tangurinho, Kaluani, Apangakigi e Waisü'ü.

16. A maioria das pessoas não conhece as relações genealógicas entre seus parentes de $\mathrm{G}+2$, e menos ainda de $\mathrm{G}+3$. Contudo, elas conhecem muitos parentes distantes em função dos vocativos utilizados por seus parentes de gerações superiores, sendo capazes de traçar relações classificatórias com inúmeras pessoas da geração de seus pais e, consequentemente, de sua própria geração. É este grande conhecimento de relações colaterais classificatórias, em contraste com a pequena memória genealógica, que chamo de « extensão horizontal » da memória kalapalo no campo do parentesco.

17. Além disso, há algumas especificidades dos Trumai que mereceriam ser comparadas mais de perto com o material Kalapalo. Segundo Monod Becquelin e Guirardello (2001, pp. 432), « a relação entre um tio materno e seus sobrinhos é tratada de modo diferente pela gramática », pois os termos de parentesco pelos quais um homem se refere a seus $\mathrm{ZCh}$ diferem daquele utilizados por uma mulher para se referir a seus BCh (uma diferença não registrada entre os outros alto-xinguanos, até onde eu saiba). As autoras também chamam a atenção para a importância do tio materno notada por Quain e a aparição indireta do MB em um canto do Jawari, no qual uma jovem diz que vai dançar com o filho de sua tia cruzada, ou seja, seu FZS para quem ela é uma MBD (ibid., p. 430). Seria fundamental investigar se e como esta distinção entre parentes patri e matrilaterais em certos pontos da terminologia pode estar ligada ao regime matrimonial trumai.

18. Galvão realizou duas idas a campo, uma em 1947 e outra em 1950. Oberg esteve entre os Kamayurá em 1948.

19. Esta ausência de dados é compreensível, já que em sua abordagem do parentesco a autora parece não estar interessada propriamente em nenhuma estrutura de aliança, mas antes nas estratégias políticas pessoais envolvidas na escolha de um cônjuge. Segundo Basso, os Kalapalo tenderiam a evitar o casamento com primos cruzados e procurariam cônjuges entre os parentes mais distantes possíveis, com os quais os laços de parentesco estariam em vias de desaparecer - reatando-os assim através do casamento. Mais do que uma estrutura, esta forma de aliança é vista por Basso como uma estratégia de ampliação das redes de apoio entre parentes distantes, procurando evitar acusações de feitiçaria ou, caso isto aconteça, garantindo abrigo entre parentes distantes de outras aldeias.

20. A terminologia para Ego feminino é basicamente a mesma, e as classificações para posições cruzadas são idênticas. O termo para « filho » $(\mathrm{S})$ é diferente, pois as mulheres se referem a seus filhos homens como umukugu (m.f.), ao invés de umugu (h.f.), e também os termos para irmã mais velha (uhasu) e irmã mais nova (uikene).

21. Se a memória kalapalo não depende do reconhecimento explícito de laços genealógicos para a definição das relações de parentesco, a análise também não deve se prender a elas. Por exemplo, os homens mais velhos de Aiha calculam seu parentesco com outras pessoas em função dos vocativos que ouviam seus avós ou pais utilizarem para outras pessoas, sem necessariamente conhecer as relações genealógicas. Assim, muitas vezes na prática faz pouca ou nenhuma diferença se Ego se refere a alguém como « irmão " porque ele é filho de alguém que seu pai chamava de « primo », ou se ele é um FBS « genealogicamente falando ».

22. Esta seria uma longa discussão, e remeto ao leitor interessado à minha dissertação de mestrado (Guerreiro Júnior 2008).

23. Basso (1973a) não distingue entre respeito (titsangi) e vergonha (ihütisu), aglutinando estes dois complexos de sentimentos e atitudes ao conceito de ifutisu (ihütisu), "vergonha ». Entretanto, os Kalapalo frequentemente afirmam ser impossível confundir respeito com vergonha em certos contextos. Por exemplo, se ambos existem face aos afins, em certas ocasiões rituais existe apenas respeito, e face aos parentes, muitas vezes os dois sentimentos devem ser tidos apenas como virtualidades (o respeito como uma possibilidade para mobilizar parentes para tarefas coletivas e a vergonha como o resultado de eventuais infrações da etiqueta). Esta distinção se assemelha àquela discutida por Viveiros de Castro (1977) entre os Yawalapíti.

24. Qualquer homem vivendo na casa de seu sogro, ou mulher vivendo na casa de sua sogra, está sujeito a bride service: é preciso trabalhar duro, e trabalhar mais do que qualquer um, se possível. 
Eventualmente, um genro pode oferecer presentes a seus cunhados ou a seus sogros (neste caso, por intermédio de sua esposa). Contudo, é só nos casamentos de noivos que a mãe do rapaz deve reunir o máximo possível de objetos valiosos (de preferência, colares de concha de caramujo; na falta destes, plumárias de excelente qualidade). Estes objetos podem ser confeccionados, cedidos por parentes próximos ou então trocados. Eles serão dados como pagamento pela noiva a todos os parentes da jovem que aparecerem na ocasião do casamento. Caso os objetos sejam insuficientes, ainda assim é preciso pagar todos os que reivindicarem, e pode levar um ano, ou até mais, para que o jovem ou sua família terminem de pagar pela noiva.

25. Curiosamente, a aldeia leva o mesmo nome da casa das flautas, em frente à qual os alto-xinguanos se reúnem na ocasião de rituais.

26. Antes mesmo da epidemia de sarampo de 1954, que dizimou boa parte da população xinguana, os Angaguhütü haviam sofrido severas perdas populacionais. Na época do contato havia apenas uma família deste grupo, vivendo entre os Kalapalo (a família do chefe).

\section{REFERÊNCIAS CITADAS}

Barcelos Neto Aristóteles

2003 "Festas para um "nobre": ritual e (re)produção sociopolítica no Alto Xingu », Estudios Latino Americanos, 23, pp. 63-90.

2006 «Doença de índio: o princípio patogênico da alteridade e os modos de transformação em uma cosmologia amazônica », Campos. Revista de Antropologia Social, 1, pp. 9-34.

2008 Apapaatai: rituais de máscaras no Alto Xingu, EDUSP/FAPESP, São Paulo.

\section{BAsso Ellen Becker}

1973a The Kalapalo Indians of Central Brazil, Holt, Rinehart and Winston Inc., New York.

1973b «The use of portuguese relationship terms in Kalapalo (Xingu Carib) encounters: changes in a Central Brazilian communications network », Language and Society, 2, pp. 1-21.

1975 « Kalapalo affinity: its cultural and social contexts », American Ethnologist, 2, pp. 207-228.

1985 A musical view of the universe: Kalapalo myth and ritual performances, University of Pennsylvania Press, Philadelphia.

1986 «Quoted dialogs in Kalapalo narrative discourse », in Joel Sherzer e Greg Urban (eds), Native south american discourse, Mouton de Gruyter, New York, pp. 119-168.

1995 The last cannibals: a South American oral history, University of Texas Press, Austin.

2001 «O que podemos aprender do discurso kalapalo sobre a "história kalapalo"? », in Bruna Franchetto e Michael J. Heckenberger (eds), Os povos do Alto Xingu: história e cultura, Editora da UFRJ, Rio de Janeiro, pp. 293-307.

Bastos Rafael José de Menezes

1983 « Sistemas políticos, de comunicação e articulação social no Alto Xingu », Anuário Antropológico, 81, pp. 43-58. 
1990 A festa da Jaguatirica: uma partitura crítico-interpretativa, $\mathrm{PhD}$ dissertation, Universidade de São Paulo, São Paulo.

1995 «Indagação sobre os Kamayurá, o Alto-Xingu e outros nomes e coisas: uma etnologia da sociedade Xinguara », Anuário Antropológico, 94, pp. 227-269.

CARdoso Marina Denise

2004 «Políticas de saúde indígena e relações organizacionais de poder: reflexões decorrentes do caso do Alto Xingu », in Esther Jean Langdon e Luiza Garnelo (eds), Saúde dos povos Indígenas: reflexões sobre antropologia participativa, Contracapa, Rio de Janeiro, pp. 195-215.

2005 Sistemas terapêuticos indígenas e a interface com o modelo de atenção à saúde: diferenciação, controle social e dinâmica sócio-cultural no contexto alto xinguano [research project], Universidade Federal de São Carlos/CNPq, São Carlos.

\section{Clastres Pierre}

2003 «Troca e poder: filosofia da chefia indígena », in Pierre Clastres (ed.), A sociedade contra o Estado, Cosac \& Naify, São Paulo, pp. 45-63.

Coelho de Souza Marcela Stockler

1992 Faces da afinidade: um estudo bibliográfico do parentesco xinguano, Universidade Federal do Rio se Janeiro, Rio de Janeiro.

1995 « Da complexidade do elementar: para uma reconsideração do parentesco xinguano », in Eduardo Viveiros de Castro (ed.), Antropologia do parentesco: estudos Ameríndios, Editora da UFRJ, Rio de Janeiro, pp. 121-206.

2001 «Virando gente: notas a uma história aweti», in Bruna Franchetto e Michael J. Heckenberger (eds), Os povos do Alto Xingu: história e cultura, Editora da UFRJ, Rio de Janeiro, pp. 358-400.

2002 O traço e o círculo: o conceito de parentesco entre os Jê e seus antropológos, $\mathrm{PhD}$ dissertation, Universidade Federal do Rio de Janeiro, Rio de Janeiro.

Costa Luiz Antonio

2007 As faces do jaguar: parentesco, história e mitologia entre os Kanamari da Amazônia Ocidental, PhD dissertation, Universidade Federal do Rio de Janeiro, Rio de Janeiro.

Descola Philippe

2001 "The genres of gender: local models and global paradigms in the comparison of Amazonia and Melanesia ", in Thomas Gregor e Donald Tuzin (eds), Gender in Amazonia and Melanesia: an exploration of the comparative method, University of California Press, Berkeley, pp. 91-114.

Dole Gertrude

1969 "Generation kinship nomenclature as an adaptation to endogamy ", Southwestern Journal of Anthropology, 2, pp. 105-123.

Fausto Carlos

1995 «De primos e sobrinhas: terminologia e aliança entre os Parakanã (Tupi) do Pará ", in Eduardo Viveiros de Castro (ed.), Antropologia do parentesco: estudos Ameríndios, Editora da UFRJ, Rio de Janeiro, pp. 61-119. 
1999 «Of enemies and pets: warfare and shamanism in Amazonia », American Ethnologist, 26 (4), pp. 933-956.

FRANCHETTO Bruna

1986 Falar Kuikuro: estudo etnolingüístico de um grupo karib do Alto Xingu, tese de doutorado, Universidade Federal do Rio de Janeiro, Rio de Janeiro.

1993 "A celebração da história nos discursos cerimoniais kuikuro (AltoXingu) », in Eduardo Viveiros de Castro e Manuela Carneiro da Cunha (eds), Amazônia: etnologia e história indígena, EDUSP/FAPESP, São Paulo, pp. 95-116.

2000 «Rencontres rituelles dans le Haut-Xingu: la parole du chef », in Aurore Monod Becquelin e Philippe Erikson (eds), Les rituels du dialogue. Promenades ethnolinguistiques en terres amérindiennes, Société d'ethnologie, Nanterre, pp. 481-509.

GALVÃo Eduardo

1979 Encontro de sociedades, Paz e Terra, Rio de Janeiro.

Godelier Maurice, Thomas R. Trautmann e Franklin Tuon Sie Fat

1998 «Introduction », in Maurice Godelier, Thomas R. Trautmann e Franklin Tjon Sie Fat (eds), Transformations of kinship, Smithsonian Institution Press, Washington, pp. 1-26.

Gow Peter

1991 Of mixed blood: kinship and history in Peruvian Amazonia, Oxford University Press, Oxford.

1997 «O parentesco como consciência humana: o caso dos piro », Mana, 2, pp. 39-65.

GREGOR Thomas

1977 The Mehinaku: the drama of daily life in a Brazilian indian village, University of Chicago Press, Chicago.

2001 «Casamento, aliança e paz intertribal », in Bruna Franchetto e Michael J. Heckenberger (eds), Os povos do Alto Xingu: história e cultura, Editora da UFRJ, Rio de Janeiro, pp. 175-192.

GuERREIRo JúNIOR Antonio Roberto

2008 Parentesco e aliança entre os Kalapalo do Alto Xingu, dissertação de mestrado, Universidade Federal de São Carlos, São Carlos

HeCKenberger Michael J.

2001 «Estrutura, história e transformação: a cultura xinguana na longue durée, 1000-2000 d.C », in Bruna Franchetto e Michael J. Heckenberger (eds), Os povos do Alto Xingu: história e cultura, Editora da UFRJ, Rio de Janeiro, pp. 21-62.

2005 The ecology of power: culture, place, and personhood in the Southern Amazon, A.D. 1000-2000, Routledge, New York.

HÉRITIER Françoise

1981 L'exercice de la parenté, Gallimard, Paris. 
Houseman Michael e David. R. White

1996 «Structures réticulaires de la pratique matrimoniale », L'Homme, 36 (139), pp. 59-85.

LEACH Edmund Ronald

1951 "The structural implications of matrilateral cross-cousin marriage », The Journal of the Royal Anthropological Institute of Great Britain and Ireland, 1-2, pp. 23-55.

LÉvi-STRauss Claude

1986 Minhas palavras, Brasiliense, São Paulo.

2003 As estruturas elementares do parentesco, Vozes, Petrópolis.

Lima Tânia Stolze

2005 Um peixe olhou para mim: o povo Yudjá e a perspectiva, ISA/Editora Unesp/NuTI, São Paulo/Rio de Janeiro.

LOUNSBURY Floyd

1964 «The structural analysis of kinship semantics », in Horace G. Lunt (ed.), Proceedings of the ninth International Congress of Linguists, Mouton, The Hague, pp. 1073-1093.

MCCALlum Cecilia

1996 «Morte e pessoa entre os Kaxinawá », Mana, 2, pp. 49-84.

Menget Patrick

1978 "Alliance and violence in the Upper Xingu », apresentado na 77th Annual meeting of the American Anthropological Association, Los Angeles.

1985 "Jalons pour une étude comparative», Journal de la Société des Américanistes, 71, pp. 131-141.

2001 Em nome dos outros, Assirio e Alvim, Lisboa.

Monod BeCQuelin Aurore e Raquel Guirardello

2001 « Histórias Trumai », in Bruna Franchetto e Michael J. Heckenberger (eds), Os povos do Alto Xingu: história e cultura, Editora da UFRJ, Rio de Janeiro, pp. 401-443.

MuRDOCK George P.

1934 « Kinship and social behavior among the Haida », American Anthropologist, 36 (3), pp. 355-385.

Murphy Robert e Buell QuAIN

1955 The Trumai Indians of Central Brazil, University of Washington Press, Seattle.

Novo Marina Pereira

2008 Os agentes Indígenas de saúde do Alto Xingu, dissertação de mestrado, Universidade Federal de São Carlos, São Carlos.

Oberg Kalervo

1953 Indian tribes of Northern Mato Grosso, Smithsonian Institution, Washington. 
Powell Harry. A.

1960 "Competitive leadership in Trobriand political organization », The Journal of the Royal Anthropological Institute of Great Britain and Ireland, 1, pp. 118-145.

1969 «Genealogy, residence and kinship in Kiriwina », Man, 2, pp. 177-202.

SCHNEIDER David

1965 " Some muddles in the models: or, how the system really works », in Michael Banton (ed.), The Relevance of models for social anthropology, Tavistock Publications, London, pp. 25-85.

STRATHERN Marilyn

1985 « Kinship and economy: constitutive orders of a provisional kind », American Ethnologist, 2, pp. 191-209.

1999 Property, substance and effect: anthropological essays on persons and things, The Athlone Press, London.

2006 gênero da dádiva: problemas com as mulheres e problemas com a sociedade na Melanésia, Editora da Unicamp, Campinas.

TAYLOR Anne Christine

1998 « Jivaro kinship - Simple and complex formulas: a dravidian transformation group ", in Maurice Godelier, Thomas R. Trautmann e Franklin Tjon Sie Fat (eds), Transformations of kinship, Smithsonian Institution Press, Washington, pp. 187-213.

Trautmann Thomas R. e Robert H. BARnES

1998 "Dravidian", "Iroquois" and "Crow-Omaha" in North American perspective ", in Maurice Godelier, Thomas R. Trautmann e Franklin Tjon Sie Fat (eds), Transformations of kinship, Smithsonian Institution Press, Washington, pp. 27-58.

Viveiros de CASTRo Eduardo

1977 Indivíduo e sociedade no Alto Xingu: os Yawalapíti, dissertação de mestrado, Universidade Federal do Rio de Janeiro, Rio de Janeiro.

1993a «Alguns aspectos da afinidade no dravidianato Amazônico », in Eduardo Viveiros de Castro e Manuela Carneiro da Cunha (eds), Amazônia: etnologia e história indígena, EDUSP/FAPESP, São Paulo, pp. 150-210.

$1993 \mathrm{~b}$ «Structures, régimes, stratégies », L’Homme, 33 (125), pp. 117-137.

1996 «Images of Nature and Society in Amazonian Ethnology », Annual Review of Anthropology, 25, pp. 179-200.

1998 «Dravidian and related kinship systems », in Maurice Godelier, Thomas R. Trautmann e Franklin Tjon Sie Fat (eds), Transformations of kinship, Smithsonian Institution Press, Washington, pp. 332-385.

2001 «GUT feelings about Amazonia: potential affinity and the construction of sociality », in Laura Rival e Neil Whitehead (eds), Beyond the visible and the material: the amerindianization of society in the work of Peter Rivière, Oxford University Press, Oxford, pp. 19-43.

2002a "Atualização e contra-efetuação do virtual: o processo do parentesco », in Eduardo Viveiros de Castro (ed.), A inconstância da alma selvagem, Cosac \& Naify, São Paulo, pp. 401-455. 
2002b «Perspectivismo e multinaturalismo na América indígena », in Eduardo Viveiros de Castro (ed.), A inconstância da alma selvagem, Cosac \& Naify, São Paulo, pp. 345-399.

Viveiros de Castro Eduardo e Carlos Fausto

1990 "Princípios e parâmetros: um comentário a L'Exercise de la parenté ", Comunicação do PPGAS, 17, pp. 1-100, Rio de Janeiro.

1993 «La puissance et l'acte: la parenté dans les basses terres d'Amérique du Sud », L'Homme, 33 (126-128), pp. 141-170.

WAGNER Roy

1967 The curse of souw: principles of Daribi clan definition and alliance in New Guinea, University of Chicago Press, Chicago.

1977 «Analogic kinship: a Daribi example», American Ethnologist, 4, pp. 623-642.

\section{ZARUR George}

1975 Parentesco, ritual e economia no Alto Xingu, FUNAI, Brasília. 